\title{
LA ACTIO LEGIS AQUILIAE: CONCEPTO, CARACTERÍSTICAS Y DESARROLLO DECRETAL POSTERIOR. LECTURAS DESDE EL CAPÍTULO TERCERO
}

\section{Cristián Eduardo AEdo Barrena ${ }^{*}$}

RESUMEN: El artículo consta de dos partes claramente diferenciadas, pero relacionadas entre sí. En la primera se analiza el concepto y las principales características de la acción de la lex Aquilia, deteniéndonos especialmente en la naturaleza penal de la misma y las lecturas que se derivan desde las distintas tesis del capitulo tercero. En la segunda parte, se estudia el desarrollo decretal de la acción, mediante las acciones in factum y las útiles, deteniéndonos en la gran discusión que la doctrina romanista mantiene sobre su concepto, sin pretender adentrarnos en los casos en los que se desarrolló la acción.

PALABRAS CLAVE: Acción - capítulo tercero - acciones in factum - acciones útiles.

\section{ACTIO LEGIS AQUILIAE: CONCEPT, CHARACTERISTICS AND ITS LATER DEVELOPMENT THROUGH DECREES. INTERPRETATIONS ON THE THIRD CHAPTER}

ABSTRACT: The article consists of two clearly distinct but interrelated parts. The first one analyzes the concept and main features of the action of lex Aquilia, stressing the criminal nature of it and the interpretations derived from the different thesis of the third chapter. The second part explores the development of the legal action by means of decrees, through the in factum and useful actions, to review in detail the civil law concept that the Roman doctrine maintains of its, without looking into those cases in which the legal action developed.

Abogado y profesor de Derecho Civil de la Universidad Católica del Norte (Chile). Diploma de Estudios Avanzados por la Universidad de Deusto (Espańa). Actualmente trabajando en su tesis doctoral en la Universidad de Deusto (España), bajo la dirección del Prof. Dr. Ricardo de Angel Yagüez. Becario del proyecto Mecesup UCN0301 de la Universidad Católica del Norte.

Fecha de recepción: 21 de octubre de 2008.

Fecha de aceptación: 25 de junio de 2009. 
KEY WORDS: Legal action - chapter three - in factum actions - useful actions.

\section{INTRODUCCIÓN}

El objeto de este trabajo es hacer un breve repaso de las principales características de la acción de lex Aquilia, deteniéndonos especialmente en el carácter penal de la ley, en las distintas visiones que sobre dicha naturaleza penal originaria han expresado los romanistas modernos y la forma en la que tales puntos de vista provienen desde distintas lecturas del capítulo tercero. En una segunda parte, analizaremos brevemente cómo se amplió el campo de aplicación de la ley, a través de las acciones in factum y útiles, deteniéndonos en la gran discusión que existe sobre sus conceptos y alcances.

Como se sabe, la lex Aquilia fue un plebiscito rogado por el tribuno Aquilio ${ }^{1}$, cuya data es imprecisa, aunque parece remontarse al siglo III A.C. ${ }^{2}$. Constaba de tres capítulos. En el primero, se establecía que quien mataba injustamente a un esclavo, un cuadrúpedo o un siervo, debía pagar al dueño el más alto valor de la cosa dentro del año

I Según la declaración contenida en el propio Digesto en 9, 2, 1, 1: "Quae lex Aquilia plebiscitum est, cum eam Aquilius tribunus plebis a plebe rogarevit" ("La ley Aquilia es un plebiscito, habiéndola rogado de la plebe el tribuno Aquilio"). Para el texto en latín hemos seguido la obra de Mommsen, Theodorus; Krueger, Paulus (1988). Corpus Iuris Civiles. Volumen Primum. Instituciones. Digesta. Hildesheim: Weidmann. Los pasajes en latín del Digesto que en adelante se citen, corresponden a esta obra. Para las versiones en castellano, hemos utilizado la traducción de D'ors, Alvaro. Hernández Tejeiro, F; Fuenteseca, P.; García Garrido, M.; Burillo, J. (1968). El Digesto de Justiniano. Pamplona: Aranzadi.

La verdad es que hay una amplia discusión en relación con la datación de la ley, a la que no podemos referirnos en este trabajo. La referencia del D. 9, 2, 1, 1 a un tribuno Aquilio, no es del todo precisa, pues hubo varios. Sobre esta cuestión, véase, por todos, a Corbino, Alessandro (2005). Il danno qualificato e la lex Aquilia. Milano: Cedam, p 31. Según Cannata, Carlo Augusto. (1992). "Sul testo originale della lex Aquilia: premesse e ricostruzione del primo capo". SDHI. No 58, p 199 y ss el probable autor de la lex pudo haber sido P. Aquilius, tribuno de la plebe, a quien se le ubica alrededor del año 210 a.C. En lo que respecta a la discusión de la datación, el sector mayoritario se inclina por el ańo 286 a.C o el año 287 a.C. Hay otros que la fijan en el ańo 186 a.C.; e, incluso, otros piensan que de manera indeterminada puede ser fijada en el siglo III a.C. Para el análisis de este problema puede consultarse, entre otros, a Biscardi, Arnaldo (1967). "Sulla data della "lex Aquilia". En A.A.V.V.: Scritti in Memoria di Antonino Giuffrè. Milano: Giuffrè. Tomo I. Guarino, Antonio (1968). "La data dalla lex Aquilia". LABEO, No 14. Zimmermann, R (1996). The Law of Obligations. Roman Fundations of the Civilian Tradition. Oxford, pp 955 y ss. Cannata, Carlo Augusto (1995-1996). "Il terzo capo della "Lex Aquilia", BIDR. Nos 98-99, p 132. 


\section{anterior al acto dañoso ${ }^{3,4}$. El segundo capítulo se refería a un supuesto totalmente diverso, pues sancionaba al adstipulator (acreedor conjun-}

3 En el D. 9, 2, 2pr se señala: "Lege Aquilia capite primo cavetur: "ut qui servum servamve alienum aliemnamve quadrupedem vel pecudem iniuria occiderit, quanti id in eo anno plurimi fuit, tantum aes dare domino damnas esto" ("Por el primer capitulo de la ley Aquilia se prevé "que quien matare injustamente a un esclavo o esclava ajenos o aun cuadrúpedo o a una res, sea condenado a dar al dueño el valor máximo que tuvo aquel año"). En Gai. 3, 215 también se le menciona, en los siguientes términos: "Damni iniuriae actio constituitur per legem Aquiliam, cuius primo capite, cautum est, ut si quis hominem alienum alienamve quadrupedem quae pecudum numero sit iniuria occiderit, quanta ea res in eo anno plurimi fuit, tantum domino dare damnas esto" ("La acción de daño injusto es establecida por la ley Aquilia, en cuyo primer capitulo se dispone que si alguien mata injustamente un esclavo ajeno o un cuadrúpedo ajeno de cualquier clase de ganado, sea condenado a dar al dueño el mayor valor que esa cosa haya tenido en aquel año"). El texto, tanto en latín como en castellano, ha sido tomado de Hernández Tejero, Francisco. (Coord); Abellan Velasco, Manuel; Arias Bonet, Juan Antonio; Iglesias Redondo, Juan; Roset Esteve, Jaime (1965). Instituciones de Gayo. Edición bilingüe. Madrid: Civitas. Las referencias sucesivas estarán basadas en esta obra.

La reconstrucción de los pasajes mencionados ha presentado algunos inconvenientes para los romanistas modernos. Véase, sobre las discusiones existentes a Natali, Nuncio (1970). La lege Aquilia ossia il damnum iniuria datum. Roma: L'erma di Bretschneider, pp 23 y 24 y Cannata, Carlo Augusto (1996). Sul problema della responsabilità nel Diritto Privato Romano. Catania: Librería Editriche Torre Catania, p 212.

4 La cuestión más conflictiva que presenta el capítulo primero dice relación con el desarrollo jurisprudencial del verbo occidere. Originalmente, dicho verbo representaba la acción de matar realizada sobre el corpus del afectado. El vocablo occidere significaba tanto abatir, destruir, eliminar, hacer desaparecer, siendo el verbo matar el elemento constante. Esta acción exigía golpear hasta la muerte y, por lo mismo, el contacto físico con la víctima. Como explica Valditara, Giuseppe (1994): "Damnum iniuria datum". En AA.VV.: Derecho Romano de obligaciones. Homenaje al profesor José Luis Murga Gener. Madrid: Centro de Estudios Ramón Areces, p 841, el verbo occidere tenía en la ley una significado más preciso y técnico que el lenguaje común, estando determinado a caedere/cades, en el sentido de golpear: "Occidere era anzi ricollegato alla medesima radice di caederelcaedes nel senso di percuoterelpercossa, contenendo dunque in sè, come elemento qualificante, il riferimento ad uniazione materialmente svolgentesi sul corpus danneggiato". En el mismo sentido, Zimmermann (1996) 978.

La evolución jurisprudencial es explicada por Castresana, Amelia (2001). Nuevas lecturas de la responsabilidad aquiliana. Salamanca: Ediciones Universidad de Salamanca, pp. 30-32, quien indica que varias expresiones semánticas de la palabra permitieron a la jurisprudencia atenuar la exigencia de contacto directo sobre la víctima, lo que condujo, con Labeón (en la decisión contenida en D. 9, 2, 9pr), con un antecedente en Ofilio (en D. 9, 2, 9, 3), a eliminar en primer lugar la necesidad de violencia de la acción de matar. Posteriormente, con Celso va a verse perfilada la evolución jurisprudencial en torno al occidere, cuando la acción material de matar es trasladada a la ubicación de una persona en situación de muerte, en el pasaje D. 9, 2, 7, 6. En el mismo sentido, MaCCormack, Geoffrey (1982). "Juristic interpretation of the lex Aquilia". En AA.VV.: Studi in onore di Cesare Sanfilipo. Milano: Giuffrè Editore, Tomo I, pp. 266-269, quien indica que el desarrollo de la regla pudo haber sido, más o menos, de la siguiente manera: durante las últimas décadas del siglo I A.C, las acciones in factum se otorgaron en casos que no podian ser tratados como occidere (en estricto rigor, cuando para los juristas no era posible aplicar el método analógico y entonces este resultaba quebrantado). Después comenzaron a buscar un principio subyacente que fijara el criterio para otorgar una actio legis o una actio in factum. Hasta antes de la concreción de la fórmula parece haber habido entre los juristas un amplio margen de apreciación para determinar cuándo otorgar una actio in factum y cuándo no. En un sentido similar, Z Paola (2000). L'imputazione del danno aquiliano. Tra iniuria e damnum corpore datum. Padova: Cedam, pp. 150-151, quien señala: "Celso, dunque, dice che è molto importante distinguere 


\section{to) que daba por pagada la deuda en perjuicio o fraude del acreedor principal $^{5}$.}

tra colui che ha ucciso (occiderit) e colui che ha dato causa alla morte (mortis causam praestitit), perché colui che ha dato causa alla morte non è tenuto in base alla lex Aquilia ma con una actio in factum". A esta explicación llega Celso a través de dos ejemplos. En uno de ellos se otorga la actio in factum por la muerte causada por la introducción de un medicamento, respecto del que la autora hace una análisis comparativo con el caso propuesto por Labeón, de la introducción de un veneno en una esclava. Así, según MacCormack, Geoffrey (1975). "Aquilian Studies". SDHI. No 41, pp. 21-24, Celso es el primer jurista que extrajo de los casos de dańo causado non corpore una regla determinante respecto de cuándo procedía la acción de la ley Aquilia y cuándo una actio in factum, pero más adelante reconoce que el criterio de Celso era difícil de aplicar en la práctica: "Celsus' distinction between occidere and mortis causam praestare is verbally neat but may not have been easy to operate in practice".

En la mayoría de los casos en los que no hubo causalidad directa se otorgaba una acción in factum. Un magnífico ejemplo es el caso de la comadrona en D. 9, 2, 9. Según Labeón, si esta proporcionaba directamente el medicamento, había acción directa; si hacía que lo tomara directamente la víctima, actio in factum. Lo reiteraba Ulpiano, en D. 9, 2, 9, 1, utilizando la analogía. Por el contrario, hay algunos supuestos en los que se concedía la acción directa, aun cuando la causalidad era mediata, como en la opinión de Próculo, en el caso en que se irrita a un perro para que muerda a otro, en D. 9, 2, 11, 5. Sin duda alguna, este uno de los principales problemas que presenta la evolución jurisprudencial del capítulo primero, pues resulta difícil conciliar o explicar satisfactoriamente las decisiones de estos juristas. Y en ello hay varias opiniones que no pueden ser desarrolladas en este lugar. Sin perjuicio de lo anterior, hay algunas bastante interesantes que podemos reseńar. Por ejemplo, hemos visto cómo MacCormack considera que la fórmula de Celso se desarrolló durante los dos primeros siglos a.C. y antes de quedar fijada, los juristas tenían un amplio margen para determinar cuándo se otorgaba, y cuándo no, una actio in factum. Y así, algunas de las decisiones que hemos citado, que parecen oponerse al criterio de Celso o que son al menos oscilantes, pertenecen a juristas anteriores al mismo, bien republicanos, bien clásicos anteriores a Celso. Por ejemplo, la decisión de Ofilio en D. 9, 2, 9, 3, jurista republicano, sigue el criterio de Celso, porque como hemos visto, los autores están de acuerdo que su decisión puede citarse como precedente de la regla y lo mismo ocurre con Labeón, jurista clásico anterior, que parece ser el siguiente paso de la cadena.

Pero otras opiniones de juristas republicanos o clásicos anteriores a Celso utilizan un criterio distinto. Una de las decisiones más antiguas pertenece al jurista republicano Bruto, que se ubica durante el siglo II a.C., quien en D. 9, 2, 27, 23, se decide por una acción directa. La decisión más próxima a Celso es la Sabino, jurista clásico quien en D. 9, 1, 1, 4 se decidía por una actio legis. Para terminar de delinear el cuadro, coincidentemente Juliano, jurista clásico posterior a Celso, a quien debemos suponer conocedor de la regla, en el pasaje de Próculo, en D. 9, 2, 11, 5, se decide por la actio in factum para un problema de causalidad mediata y solo concede la acción directa en contra de quien sostenía con su mano al perro que dańa a otro. En cambio, otros autores han argumentado que la culpa fue utilizada como criterio que servía para la resolución de estas cuestiones, es decir, que los juristas romanos se valieron de materiales culpabilísticos cuando la causalidad no se presentaba idónea (o derechamente no existía) para atribuir responsabilidad a un sujeto y ello explicaría la diferenciación entre acción directa, versus actio in factum para casos semejantes. Véase, por todos a. Zilioto (2000) $126 ; 139$, quien sostiene que en caso de concurrir diversos factores causales, algunos juristas, como Servio, Mela y Alfeno, utilizaron el elemento subjetivo como determinante para resolver el problema causal. En tales textos, sostiene que la jurisprudencia otorgó siempre la actio directa; en cambio, cuando las decisiones ponían el acento en la conducta y no en el elemento intencional. No obstante, explicando la contradicción de Próculo seńala que este, en el caso del perro irritado, 11,5, habría seguido la tradición: "Tuttavia sembra che più elástica soluzione offerta da Proculo nel caso del cane aizzato si possa riallaciare alla tradizione di concedere l'azione civile in casi similari, quali ad esemplio quelli già menzionati del telum o dell'asino che sfugge (vedi Alfeno, D. 9, 2, 52, 2) o quello ricordato da Ulpiano in D. 9, 1, 1, 6".

El Digesto solo le dedica el pasaje contenido en D. 9, 2, 27, 4 para destacar que cayó poste- 
Finalmente, el problemático capítulo tercero se encuentra mencionado en dos pasajes. En D. 9, 2, 27, 5 y en Gai. 3, 2176. También hay una mención a la sanción en Gai. 3, 218 . Es imposible reseńar con detalle en

riormente en desuso: "Huius legis secundum quidem capitulum in desuetudinem abiit" ("El segundo capitulo de esta ley cayó en desuso"). La otra fuente es la del pasaje de Gai. 3, 215: "Capite secundo <adversus > adstipulatorem qui pecuniam in fraudem stipulatoris acceptam fecerit, quanti ea res est, tanti actio constituitur" ("En el segundo capitulo se establece una acción contra el coestipulante que se hubiera dado por pagado en fraude del estipulante"). La razón por la cual cayó en desuso está contenida en el texto siguiente de Gai. en 3, 216: "Quae et ipsa parte legis damni nomine actionem introduci manifestum est; sed it caveri non fuit necessarium, cum actio mandati ad eam rem sufficeret; nisi quod ea lege adversus infitiantem in duplum agitur" ("Es evidente que en esa parte misma de la ley se ha introducido tal acción a título de daño; pero esto no era necesario disponerlo, ya que bastaba para ello la acción de mandato, aunque por esta ley se puede ejercitar una acción al doble contra el demandado que niega el hecho"). Sobre los problemas relativos a este capítulo, especialmente los esfuerzos por buscar una base común con los otros dos capítulos, puede consultarse a Cannata, Carlo Augusto (1994). "Considerazioni sul testo e la portata originaria del secondo capo della "lex Aquilia". Index. № 22. Grosso, Giuseppe (1964). "La distinzione fra "res corporales" e "res incorporales" e il secondo capo della lex Aquilia". En AA.VV.: Synteleia Vicenzio Arangio Ruiz. Napoli: Editore Jovene Napoli.

En el primero, se señala: "Tertio autem capite ait eadem lex Aquilia: "Certerarum rerum praeter hominem et pecudem occisos si quis alteri damnum faxit, quod usserit fregerit ruperit iniuria, quanta ea res erit (fuit) in diebus triginta proximis, tantum aes domino dare damnas esto" ("La misma ley Aquilia dice en el tercer capitulo: "respecto de las demás cosas, sea de esclavo y res que hayan sido muertos, si alguien hiciere daño a otro porque hubiere quemado, quebrado o roto injustamente, sea condenado a dar al dueño el valor que la cosa alcance en treinta dias próximos"). En cuanto al texto gayano: "Capite tertio de omni cetero damno cauetur. Itaque si quis seruum uel eam quadrupedem, quae pecudum numero est <vulneraverit siue eam quadrupedem, quae pecudum numero non est $>$, uelut canem, aut feram bestiam, uelut ursum, leonem uulnauerit uel occiderit, hoc capite actio constituitur. In ceteris quoque animalibus, item in omnibus rebus, quae anima carent, damnum iniuria datum hac parte uindicartur. Si quid enim ustum aut ruptum aut fractum <fuerit>, action hoc capite constituitur, quamquam potuerit sola rupti appellation in omnes istas causas sufficere; ruptum <enim intellegitur, quod quoquo modo corruptum> est; unde non solum usta (aut rupta) aut fracta, sed etiam scissa et colissa et effusaet quoquo modo uitiata aut perempta atque deteriora facta hoc uerbo continentur" "En el tercer apartado se prevé todo sobre otro tipo de daño: si alguien o matara a un esclavo, o una pieza de ganado, o incluso no de ganado; por ejemplo un perro, o una fiera, oso o león. También castiga esta parte de la ley el daño causado injustamente a cualquier otro animal o cosa inanimada. Hay pues, acción para el caso de que algo fuera quemado, roto o estropeado, aunque para ello basta con la denominación de "roto", ya que se entiende que dentro de lo roto está incluida cualquier cosa que fuera estropeada de otro modo. Por lo tanto, se incluyen dentro de esta palabra las cosas quemadas, rotas, partidas, golpeadas, derramadas, y todas las que hayan sido estropeadas, destruidas o deterioradas").

7 "Hoc tamen capite non quanti in eo anno, sed quanti in diebus XXX proximis ea res fuerit damnatur is qui damnum dederit. Ac ne "plurimi"quidem uerbum adicitur; et ideo quidam putauerunt liberum esse iudici uel ad id tempus ex diebus XXX aestimationem redigere, quo plurimi res fuit, uel ad id quo minoris fuit. Sed Sabino placuit proinde habendum ac si etiam hac parte "plurimi" uerbum adiectum esset; nam legis latorem contentum fuisse, quod prima parte eo uerbo usus esset" " "Sin embargo, en este capitulo, el que ha causado el daño no es condenado por lo que la cosa valiera en aquel año, sino por el valor que hubiera tenido en los últimos treinta dias. $Y$ además no se añade la palabra "máximo", por lo que algunos pensaron que el juez tiene libertad para fijar la estimación dentro de los treinta dias, ya sea el valor máximo de la cosa, ya sea el valor minimo. Pero a Sabino le pareció que habia que suponer que también en esta parte de la ley se habia añadido la palabra "máximo" porque el legislador se dio por satisfecho con haber utilizado esta palabra en la primera parte"). 
este trabajo la enorme discusión que existe en esta materia, pero el propósito de resumirla, brevemente, es la incidencia que tiene en la materia en análisis, como luego veremos.

En efecto, en el capítulo tercero establecía que en caso que el daño proviniera de una conducta que consistiera en quemar, quebrar o romper (urere, frangere, rumpere), se debía indemnizar con el valor que la cosa hubiese tenido dentro del período de los 30 días. La cuestión es que no está claro el período dentro del cual debía ser considerada dicha sanción. El pasaje de Gayo 3, 218 utiliza la expresión fuerit en una oportunidad y fuit en dos y en el D. 9, 2, 29, 8, se emplea el verbo fuit. Ambos verbos son indicativos que la sanción tendría que haber sido estimada hacia el pasado, entendiéndola dentro de los 30 días anteriores al daño. Como desde este punto de vista habría una equiparación completa con el capítulo primero, también queda lógicamente explicada la indicación del mismo D. $9,2,29,8$, con arreglo al cual debía ser considerado en el capítulo tercero la expresión plurimi, es decir, que la indemnización, cualquiera fuera el perjuicio inferido, debía comprender el más alto valor de la cosa.

El problema es que dichos pasajes se contradicen aparentemente con el texto del D. 9, 2, 27, 5, que utiliza la partícula erit, en cuyo caso la sanción debía ser entendida como dentro de los 30 días siguientes. Tales contradicciones han dado lugar a las más variadas teorías. En principio y para los propósitos de este trabajo, baste citar la sistematización de MacCormack: ${ }^{8}$ a) que en el tiempo que la ley fue aprobada, así como en el derecho clásico, el demandante no recibía el más alto valor del esclavo o de la cosa dańada, sino que el juez valoraba la pérdida por referencia a dicho más alto valor, dentro de los 30 días precedentes al acto que causa el dańo. Esta correspondería a la tesis de Monro; b) que el tercer capítulo, al tiempo de su promulgación, solo trataba la destrucción de objetos inanimados y proveía como sanción el más alto valor dentro de los 30 días precedentes a la causa del perjuicio. Esta es la tesis de Jolowicz; c) que el tercer capítulo, al tiempo de su promulgación, se refería solo a las heridas de los esclavos y del ganado, de modo que el demandante podía recuperar las consecuencias de dichas heridas, dependiendo de la evolución de estas, fijándose el período de los 30 días siguientes al acto dañoso. Es la teoría opuesta a Jolowicz, defendida por Daube; d) según una cuarta teoría, sustentada por Iliffe, entre otros, el capítulo tercero, al tiempo de su promulgación, se refería a las más serias heridas y daños causados al esclavo y ganado, así como a objetos inanimados, respectivamente, estableciendo como sanción el más alto valor dentro de los 30 días anteriores a la comisión del ilícito. 
Nosotros entendemos que las posiciones doctrinales básicamente pueden agruparse con las signadas con las letras a) y b), es decir, los modelos de Monro y Jolowicz dentro de un grupo, como opuestos a Daube? Fuera de estas dos tesis antagónicas, a nuestro juicio hay un tercer grupo, en el que pueden agruparse autores que aportan tesis intermedias o derechamente escépticas, como Iliffe, hasta aquellos que desarrollan opiniones propias, como Valditara, equidistante de ambas, quien considera el capítulo tercero como un módulo general de daños. Finalmente, Kelly es quien presenta la aproximación que juzgamos más original, pues estima que el período de 30 días no fue establecido para la valoración o cálculo de la indemnización, sino que, asocia el plazo con el tiempo durante el cual debía pagar la indemnización, antes de ser ejecutado por la manus iniectio $^{10}$.

9 La mayoría de los autores considera que la sanción estaba referida hacia el pasado; entre otros y por todos, Jolowicz, H.F, (1922). "The original scope of the lex Aquilia and the question of damages". LQR. No 38, pp 220 y ss. VAN Warmelo, Paul, (1980). "A propos de la loi Aquilia". RIDA. No 27, pp 345-348. MacCormack (1970) 165 ss. Más recientemente, Cannata (1995-1996) 120 y ss. También en Cannata (1996) 109-110, quien se inclina por la tesis de Jolowicz. Gran parte de estos autores consideran que la otra tesis, de Daube, se funda en un error de trascripción del texto de Ulpiano en D. 9, 2, 27, 5, que contendría erróneamente la expresión erit, pero el trabajo más profundo en esta línea sin duda alguna pertenece a ANKUM, Hans (1983): "Quanta ea res erit in diebus XXX proximis dans le troisième chapitre de la lex Aquilia: un fantasme florentin". En AA.VV.: Mélanges en Hommage a Jacques Ellul. Religión, société et politique. París: Press Universitaires de France, pp 179 y ss, explicando que la expresión se debe a un error del manuscrito Florentino.

En cuanto a la doctrina contraria, fue promovida por DaUBE, David (1936). "On the third chapter of the lex Aquilia". LQR. No 52, pp 253-255 y en DaubE, David (1969). Roman Private law. Linguistic, social and philosophical aspects. Edinburgh: Edinburgh University Press, pp 66 y ss. Le siguen, entre otros, Cardiasca, G (1974). "La portée primitive de la Loi Aquilia". En Watson, Alan (ed.): Daube Noster. Essays in legal history for David Daube. Edinburgh: Scottish Academic Press, p 62 y Watson, Alan (1965). The law of obligations in the later Roman republic. London: Clarendon Press, p 235 y en Watson, Alan (s.d.). Roman Private Law around 200 BC. Edinbugh: Edinburgh University Press, p 153, sostiene que la teoría de Daube es la más satisfactoria en relación con el carácter originario del capítulo tercero.

10 La tesis escépticas o bien que se apartan de las otras dos han sido sustentadas, entre otros, por los siguientes autores. Para Iliffe (1958). "Thirty days hath lex Aquilia". RIDA. $3^{\text {a }}$ serie, Tomo V, pp 496 y ss, aun cuando la tesis de Daube es la más satisfactoria explicación para el capítulo tercero, por cuanto, a diferencia del carácter penal del primero, este tendría por objeto permitir una adecuada valoración de las heridas, frente a la ausencia de listas o periódicos que fijaran listas de mercado, a diferencia del autor inglés estima que la lex desde un comienzo incluía tanto a los seres animados como inanimados y que en ambos casos la valoración cumplía el mismo papel. Pugsley, David (1982). "On the lex Aquilia and culpa". $T R$. No 50, pp 1-6 considera que los juristas clásicos utilizaron la sanción hacia al pasado, al igual que en el capítulo primero, pero rechaza su fundamentación en el pretendido carácter penal de la lex, considerando que dicho período tenía por función determinar el valor de acuerdo al costo de contratación de los esclavos o bienes animados heridos, lo que constituiría una gran mejora en relación con penas fijadas en las XII Tablas, Kelly, John (1964). "The meaning of the lex Aquilia". $L Q R$. No 80, pp 82 y ss y KelLy, John (1971). "Further reflections on the lex Aquilia". En AA.VV. Studi in onore di Edoardo Volterra. Milano: Giuffrè Editore. Vol. I, pp 235-239, propone una nueva reconstrucción del capítulo. En efecto, 
Estas teorías sobre el capítulo tercero son en verdad dos maneras distintas de comprender la ley. Las discusiones sobre el capítulo tercero son fundamentales para determinar el carácter originario de la ley y su desarrollo, de ahí que a nuestro juicio resulte justificado detenerse especialmente en esta cuestión. Desde luego, hay numerosísimos puntos de contacto entre las diferentes teorías, pero también muchas son las diferencias. Estas visiones influyen sobre el desarrollo la concepción originaria de la ley y el desarrollo pretoriano de los verbos, sobre las diferencias en la forma en la que se entiende la valoración de los perjuicios, la consagración y la evolución de la fórmula id quod interest, además de las vinculaciones de la lex Aquilia con los delitos anteriores, tratándose de los verbos del tercer capítulo y su equivalencia o no con los delitos de iniuria de las XII Tablas. Al concepto y características de la acción, así como al concepto de las acciones in factum y útiles nos referiremos en los apartados siguientes, en los que haremos referencia a estas distintas lecturas desde el capítulo tercero, en lo que sea pertinente.

\section{1) LA ACTIO LEGIS AQUiLIAE: CONCEPTO Y CARACTERÍSTICAS. ¿TENÍa NATURALEZA PENAL LA LEX AQUILIA?}

En un comienzo, siguiendo a García Garrido, la Ley Aquilia otorgó la actio legis aquiliae"1. Explica: “...en las legis actiones se consigue una manus iniectio, para obligar al demandado al pago de la pena. En la acción formularia que la sustituye, se concede el valor máximo de la cosa dañada (in simplum) contra el que confiesa el hecho y contra el que lo niega, por efecto de la litiscrescencia, el doble (in duplum). Según Gayo, 4.9 era una acción mix-

según su opinión, en el pasaje de Ulpiano en D. 9, 2, 27, 5 podía ser sustituida la expresión "damnum faxit" por "iniuria faxit", extrayendo la palabra iniuria desde su ubicación posterior a sus verbos (que al autor no le parece original) y luego separando la frase de la siguiente manera: "Si quis alteri iniuriam faxit/l quod usserit fregerit ruperit /l quati ea res erit // in diebus XXX proximis tantum aes dare damnas esto", para arribar a la consecuencia de que el período estuvo ligado a la manus iniectio y no directamente a la valoración de pérdidas.

Finalmente, VALDitara (1994) $822 \mathrm{ss}$, criticando ambas posiciones (más exactamente las de Daube y Jolowicz-Cannata), estima que la valoración era hacia el pasado (pues la partícula erit utilizada en D. 9, 2, 27, 5 se debería a un error de trascripción) y además dicha valoración comprendía tanto a los bienes inanimados como animados, erigiéndose el capítulo tercero en una cláusula general de daños. Una mayoría de autos italianos siguen esta línea, con la excepción de Cannata. Véase Pugliese, Giovanni (1991). Istituzioni di Diritto Romano. 3a Edición. Torino: Giampichelli Editore, p 605 y BIONDI, Biondo (1965). Istituzioni di Diritto Romano. 4a Edición. Milano: Giuffrè Editore, pp 528-531.

11 Según Arangio Ruiz, V (1945). Las acciones en el derecho privado romano. Traducción de Faustino Gutiérrez Alviz. Madrid: Editorial Revista de Derecho Privado, p 11, el término actio, en Derecho romano, designaba el acto jurídico mediante el cual una persona afirmaba solemnemente su derecho, a fin de que fuera reconocido (si fue este desconocido) o bien habiendo sido reconocido fuera perturbado en su goce (de ahí que fuese realizable). 


\section{ta, pero seguía las reglas de la acción penal, ya que llevaba a la condena del valor máximo. Contiene en la pena la indemnización por el daño"l2.}

12 García Garrido, Manuel (1998). Derecho Privado Romano. Casos, acciones, instituciones. $7^{\mathrm{a}}$ Edición. Madrid: Editorial Dykinson, p 508. En el mismo sentido, D’ors, Alvaro (1997). Derecho Privado Romano. 9a Edición. Pamplona: Ediciones Universidad de Navarra, p 435. Ha de tenerse presente, como explica Volterra, Eduardo (1988). Instituciones de Derecho Privado Romano. Reimpresión $1^{\text {a }}$ Edición. Madrid: Civitas, p 233, que una vez concluida la descripción de las acciones de ley, Gayo añade -Gai. 4, 30- que todas ellas: "terminaron siendo odiadas, en cuanto que, supuesta la excesiva sibtilitas de los veteres que las habian creado, estaban ensambladas de tal modo que quien cometia el minimo error en el desarrollo de las formalidades prescritas perdia el litigio. Por esta razón, continúa, esas legis actiones fueron suprimidas por una lex Aebutia y por dos leyes Iuliae y se hizo que los juicios se desarrollaran per concepta verba, id est per formulas".

Como explica Arangio (1945) 14-15, el procedimiento romano tuvo 3 épocas: a) la época de las acciones de la ley, posiblemente en vigor desde la fundación de Roma, permaneciendo como forma ordinaria de procedimiento privado hasta la mitad del siglo II a.C.; b) la época de las "fórmulas" o del procedimiento formulario, que data de la mitad del siglo II a.C hasta el siglo III d.C; c) finalmente, la época del procedimiento extraordinario, que sustituyó en el siglo III d.C al formulario y consagrado especialmente en la codificación del Derecho romano dispuesta por Justiniano. Si bien es cierto, como acabamos de ver, las acciones de la ley fueron sustituidas por las acciones formularias, lo que no está claro y es sumamente discutido por la doctrina es la forma en la que se produjeron dichas aboliciones y a cuáles leyes, exactamente, se refiere Gayo en su pasaje. LeVY-BRUHL, H (1960). Recherches sur les actions de la loi. París: Sirey, pp 324 y ss, explica las razones del abandono de las acciones de la Ley: "On devait fatalement aboutir à una rupture. En dèpit des mesures d'assouplissement de l'ancien système, et de la crèation d'Actions de la Loi d'un type incomparablement plus moderne, comme la Judicis Postulatio ou la Condictio, il ne rèpondait plus aux besoins d'une société toute différente. Cèst la véritable raison de l'abolition du système des Actions de la Loi et de son remplacement par un système nouveau, auquel on a donné le nom de procédure formulaire". En todo caso, agrega este autor, no es cierto que las leyes a las que hace referencia Gayo hubiesen abolido completamente las acciones de la ley, como ocurrió, por ejemplo, con la acción de damnum infectum, que el autor analiza en las páginas siguientes.

Un análisis del paso de las acciones de la ley al procedimiento formulario se encuentra en Scialoja, Vittorio (1954). Procedimiento civil romano. Ejercicio y defensa de los derechos. Traducción Santiago Sentis Melendo y Marino Ayerra Redin. Buenos Aires: Ediciones Jurídicas Europa-América, pp 157 a 159. Según el autor: "Habia un momento en la legis actio en que la litis quedaba determinada y cierta entre las partes y venía a establecerse de una manera jurídica eficaz e irrevocablemente en qué esfera y bajo qué condiciones y modalidades habria de desarrollarse el juicio. En este momento se producia la litis contestatio. Ahora bien, como el juez debia, por lo hecho in iure, y más especialmente por la litis contestatio, señalar los limites y el estado de la cuestión que habia de formar el objeto de su iudicium, es probable que, a fin de facilitarle su cometido, se comenzara muy pronto a redactar una instrucción escrita que le sirviera a modo de memorial de los puntos esenciales de la litis, asi como de los términos en que habia quedado contestada entre las partes; esto, como costumbre práctica, ya que no como regla de derecho". Agrega que fue la lex Aebutia la que autorizó el sistema de que el magistrado librara una instrucción escrita o formula. Sobre el abolición del sistema de las acciones de ley y la introducción del procedimiento formularios según Gayo, señala: "La Ley Ebucia (acaso de la primera mitad del siglo VII de Roma, hacia el 630) introdujo probablemente este nuevo procedimiento sin abrogar el anterior de las legis actiones; de manera que hasta las leyes Julias tendriamos un doble sistema de procedimiento, y tal vez se podria elegir uno u otro..."."

Con mayor claridad a nuestro juicio Arangio (1945) 57-59, señala que la ley Aebutia, dictada probablemente entre los años 150 y 120 a.C, permitía la opción entre la acción de la ley y el procedimiento formulario, pero este último terminó imponiéndose en los hechos, especialmente porque el nuevo procedimiento permitía proteger relaciones no consideradas 
Según Natali, la acción se caracterizaba por ser civil, perpetua, de derecho estricto, personal; civil, en cuanto nació de un plebiscito; perpetua, porque derivaba de la ley; derecho estricto, por cuanto no era concedida por el pretor; personal y directa contra la persona dañante, para obtener el pago de una suma de dinero; y, noxal, en algunos casos, en los que se respondía por la conducta de otro ${ }^{13}$. Con la acción se sancionaba in simplum contra el que confesaba e in duplum si el autor del dańo negaba su causación. Es lo que se conoce como la infitiatio. Hay una especial penalidad al sujeto que negaba la realización del perjuicio. Este carácter de infitiatio era propio de las acciones mixtas, como ocurría precisamente con la lex Aquilia y, siguiendo a Arangio, el redoblamiento de la indemnización se considera un residuo histórico del régimen primitivo de la aprehensión corporal ${ }^{14}$.

Como señala Martínez Sarrión, aun cuando no aparezca claramente en los textos, un análisis de fuentes literarias le hace pensar, no sin razón, que el fundamento jurídico de la penalización in duplum parece encontrarse en un animus fraudandi, no en la simple negación. Es decir, en palabras del autor: “...cuando esta negación tiene un contenido antijurídico que provoca la vulneración o el menoscabo, detrimento o desconocimiento del derecho de otra persona, a consecuencia de lo cual se conectan situaciones favorables o ventajosas para el negante; en manera tal que, el aspecto subjetivo de la negación, alcanza una función relevante, dejando relegada la situación objetiva que toda afirmación o negación encierra"15.

En cuanto al carácter penal de la acción, hay una amplia discusión en la doctrina. Se discute si esta tenía un carácter reipersecutorio, estrictamente penal o mixto. Se entiende que una acción era reipersecutoria cuando tendía a la reparación de un perjuicio sufrido en el patrimonio, seguido de la violación de un derecho, de manera que la sentencia res-

en las acciones de la ley. Más tarde, con la dictación de la ley Julia, en el año 17 a.C., abolió el derecho de opción y obligó a recurrir al procedimiento formulario, salvo en casos excepcionales. Además, agrega una cuestión interesantísima. Las fórmulas de la ley se basaban en ciertos ritos o palabras sacramentales y esa característica permitía que fueran aplicadas a varias relaciones jurídicas. En cambio, el procedimiento formulario vino a vincular la acción con el derecho subjetivo o la relación jurídica que vinculaba a las partes. Como indica el autor: "... la acción es el trazo de unión que existe entre el derecho subjetivo y el procedimiento que sirve a realizarle".

13. Natali (1970) 68.

14 Arangio (1945) 131.

15 Martínez Sarrión, Ángel (1993). Las raices romanas de la responsabilidad por culpa. Barcelona: Editorial Bosch, p 85; 105, agregando que la mera negación perdía el carácter defensivo cuando las pruebas apuntaban, sin asomo de duda, a la comisión del hecho dañoso. La fórmula de la lex Aquilia encontraría su referente en la defraudatio creditis, de manera que las fuentes literarias consultadas por el autor definen la infitiatio como un creditum fraudare. El negare atacaba la esencia misma del negocio, de ahí el especial castigo que este merecía. De otra parte, hay dudas doctrinales respecto de si la sanción infitiatio era aplicable al capítulo tercero de la lex, resumidas por MARTínez (1993) 172 ss. 
tituía dicho derecho al estado que se encontraba antes de la lesión. En cambio, la acción penal, como hemos visto antes, condenaba al autor de la ofensa a una poena, es decir, al pago de sumas superiores al monto del perjuicio material efectivamente sufrido por la víctima, de manera que a este le fuera causado un detrimento patrimonial ${ }^{16}$. Para Arangio, las acciones mixtas no encuadraban, desde un punto de vista técnico, con las dos primeras. Mientras estas eran el reflejo de la relación material existente entre las partes, la pena de la que trataban las acciones mixtas era una multa procesal infringida al demandado temerario ${ }^{17}$. Con todo, más precisamente o correctamente planteada la cuestión, siguiendo a Valditara, es la naturaleza de la acción en los orígenes de la ley, pues la jurisprudencia clásica afirmaba sin ambigüedad su carácter penal o, más bien, mixto ${ }^{18} 19$.

Así, según una lectura, en sus orígenes la ley nace para proteger al propietario, quien frente a la destrucción de la cosa no podía recurrir a la acción real emanada del dominio o rei vindicatio -que exigía la existencia actual de la cosa-, de manera que el dueño podía intentar, antes de la lex Aquilia, una actio furti, cuyo ámbito de aplicación se vio ampliado ${ }^{20}$. Por esta razón, al menos originariamente, se estableció en favor del propietario una acción personal que le permitiera obtener un crédito por el valor de la cosa destruida y por eso algunos autores afirman el carácter instrumental

Según Albanese, Bernardo (1970). Illecito (storia). Enciclopedia del diritto. Tomo XX. Milano: Giuffrè Editore, p 70, la palabra poena tenía en el Derecho romano dos sentidos precisos. En un primer sentido, poena era la aflicción conexa del ordenamiento jurídico al comportamiento antijurídico. En el segundo significado técnico, por el contrario, poena era la aflicción pecuniaria determinada, a cargo de un sujeto, en base a una obligación libremente asumida frente al otro sujeto, como ocurrió con las numerosas penas establecidas en las stipulatio.

17 Arangio (1945) 132, agregando que en el caso en que el demandado reconociera la existencia del hecho alegado por el demandante, la acción no se presentaba como reipersecutoria, pues, precisamente en la lex Aquilia eran claras las características penales de la acción.

VAlditara (1994) 877-878. Desde luego, como señala este autor, este indudable carácter penal le otorgaba las características propias de estas acciones: la intransmisibilidad hereditaria de la legitimación pasiva, la solidaridad cumulativa y la concurrencia con la acción reipersecutoria. En el mismo sentido, Cannata (1996) 8.

19 Corbino (2005) 11-12 seńala la diferencia sustantiva entre la acción rei persecutio y la acción penal. Mientras la primera era una acción real -in rem-, derivada de un derecho real, la propiedad, la acción penal era in personam, del momento que tenía como función primordial sancionar un comportamiento (aunque englobara el resarcimiento) que transgredía un derecho (el de propiedad).

20 Sin embargo, esta acción presentaba el inconveniente de exigir el dolo del demandado, a diferencia de la acción de la lex Aquilia, en la que la palabra iniuria de la ley fue interpretada ya por la primera jurisprudencia clásica en el sentido que se debía responder también por ciertos actos de negligencia que causaban dańos a otras personas. En este sentido, D'ors (1997) 436. Un ejemplo de la ampliación de la acción de hurto en los casos de destrucción de bienes o de la lex Aquilia, puede encontrarse en el pasaje del D. 9, 2, 27: "Si servus servum alienum subripuerit et occiderit, Iulianus et Celsus scribunt et furti et damni iniuriae competere actionem" "Si un esclavo hubiera raptado y asesinado a un esclavo ajeno, Juliano y Celso escriben que compete la acción de hurto y la de daño injusto"). 
de la acción penal, que no se traducía únicamente en una finalidad sancionadora $^{21}$. No deja de tener sentido entonces que Sohm considere que la acción aquiliae es una acción derechamente reipersecutoria, aunque por el carácter especial que en ella adopta la tasación del dańo, ofrezca cierto matiz penal ${ }^{22}$, y, que la circunstancia que la ley se concediera solo al propietario, revela su inspiración fundamentalmente resarcitoria ${ }^{23}$.

El punto de vista más categórico en el sentido que venimos comentando pertenece a Cardiasca, quien siguiendo la tesis de Daube a propósito de la interpretación del capítulo tercero, afirma que en su concepto la ley Aquilia no tenía un carácter originariamente penal; por el contrario, contenía un programa preciso y determinado: proteger cierto tipo de bienes, especialmente importantes para la agricultura y el mundo rural romano, como lo eran los esclavos y las res se moventes. El progreso de la ley en relación con delitos anteriores se tradujo en un mejoramiento de los instrumentos de protección de la propiedad. Frente a atentados a los bienes más importantes, se estableció un régimen de estimación de daños sobre dos puntos neurálgicos: fluctuación estacional, dentro del ańo anterior, para el caso de muerte y la fijación de los 30 días próximos como mecanismo de determinación de evolución del daño, en presencia de lesiones o deterioros a las cosas animadas, dentro del capítulo tercero, lo que en su concepto restituye a la ley su unidad y su objetivo unívoco. Agrega que el carácter penal de la ley no era una característica originaria de la misma. Dos siglos más tarde la doctrina, por la bipartición de las obligaciones, habría conducido el damnum a la categoría de delitos ${ }^{24}$.

En un sentido similar, Pugsley ha argumentado contra su carácter originariamente penal. Indica que dicho pretendido carácter no permite

21 Entre otros, Valditara (1994) 878-879 y Castresana (2001) 27. Esta relación entre la lex Aquilia y la propiedad ha sido muy bien visualizada por CorBıno (2005) 8-9, quien señala que la acción de damnum deriva de la lesión de un derecho real, distinto de la lesión a un derecho de obligación o personal. Más adelante agrega: "Il principio generale da si osservato è stato che mentre la lesione di un diritto reale poteva dare luogo non solo ad una rei persecutio (al diritto di pretendere ciò̀ la reintegrazione nella situazione patrimoniale lesa), ma anche -ricorrendo taluni presupposti (come fu presto per il furtum, ma poi anche per una serie di altri fatti)- ad una "poena" (al diritto di pretendere cioè che l'autore della lesione subisse un'afflizione patrimoniale, talore fissa, talora invece proporzionata alla gravità del fatto e perciò fissata ora nella misura del valore della cosa -simplum-ora in quella di un múltiplo di esso: duplum, triplum, etc.), la violazione di una obbligazione non poteva ricevere altra sancione che la rei persecutio". Soнm, Rodolpho (1927). Instituciones de Derecho Privado Romano. Historia y Sistema. Traducción de la 17a Edición de W. Roces. Madrid: Revista de Derecho Privado, pp 420-421. Díaz Bautista, Antonio (2001). "La función reipersecutoria de la poena ex Lege Aquilia". En AA.VV. La responsabilidad civil de Roma al Derecho moderno. Burgos: Ediciones Universidad de Burgos, pp 272 y ss. Sobre el carácter original del texto de la lex y las posibles alteraciones posteriores de este, puede consultarse, con la bibliografía consultada a ZiLioto (2000) 4-5, en nota 8. Sobre el mismo tema, Cannata, Carlo Augusto (1992). "Delito y obbligazione". En A.A.V.V. Illecito e pena privata in età repubblicana. Napoli: Edizioni Scientifiche Italiane, pp 37-39; Castresana (2001) 25- 26. 
explicar porque la ley se refería sencillamente a múltiples daños que pudiesen ocurrir en cualquier lugar y que la conexión entre la medida de los dańos y la naturaleza penal de la acción no es temprana, sino posterior, tardía. En principio, agrega, los estatutos no describen los daños como pena. Así, por ejemplo, en Gai. 3, 214, solo se afirma que en ocasiones la compensación excedía el daño causado. Solo Justiniano, en sus Instituciones $(J, 4.3 .9)$ la trata como poena, por cuanto el demandado a veces era condenado a una suma mayor. Por el contrario, piensa que el mayor valor establecido en el capítulo primero fue aceptado como un maximum y el juez tenía discreción para fijar la suma a indemnizar y que, en todo caso, se trataría de una medida o evaluación del dańo que podría hacer una diferencia en algunos casos ${ }^{25}$.

Un buen exponente de la concepción originaria de la lex con carácter penal es Albanese. Para este autor, la lex Aquilia va a representar la evolución de la vieja concepción de la pena a una de carácter resarcitorio; de la pena entendida como aflicción personal del dañante, a través de un largo recorrido, se concluyó en un verdadero resarcimiento. Se trataría de un fenómeno singular del Derecho romano, en el que el desarrollo histórico permitiría llegar a un punto de equilibrio entre el ilícito penal y el no penal. El resultado es lo que denomina un "monstruo conceptual": la pena in simplum, la pena resarcitoria.

El autor hace un estudio de las fuentes. Pasando por el esquema de Cassio, hasta el pensamiento de Gayo, quien hace una contraposición neta entre acción penal y reipersecutoria, terminando con Justiniano, en que se evita una rigurosa contraposición entre acciones penales y reipersecutoria, de manera de considerar la acción de la lex Aquilia reipersecutoria, precisamente cuando no se ve diferencia de valor entre el objeto dańado en el período de tiempo previsto de la ley. Esto se traduce en una paulatina despenalización del delito privado, a través del cual se llega a la fórmula civil actual de la indemnización de todo daño ${ }^{26}$.

Pugsley (1982) 1-3.

Albanese (1970) 63-64; 72 ss. Agrega que la lex Aquilia: “...representa un paso importantisimo verso il concepto di una pena risarcitoria: all'idea ormai prevalente di risarcimento, infatti, essa congiunge tenaci aspetti afflittivi". Una opinión similar puede encontrarse en BIGNARDI, Alessandra (1997). "Frangere e rumpere nel lessico normativo en ella interpretatio prudentium". En A.A.V.V. Nozione, formazione e interpretazione del diritto. Dall'età romana alle sperienze moderne. Ricerche dedicate al professor Filippo Gallo. Napoli: Jovene Editore: Tomo I, pp 29-31.

Para Schulz, Fritz (1951). Classical Roman Law. London: Clarendon Press, pp 589-590 la ley tenía un claro carácter penal en sus orígenes. Indica que se trataba de una acción penal y no de una acción por indemnización, agregando que ni siquiera el simple valor dentro del año (capítulo primero) o de los 30 últimos días (capítulo tercero) transformó dicho carácter. Como argumento indica que si bien es cierto la acción de dolo fue in simplum, se trató sin embargo de una acción penal. Ello se traduciría, entre otras características propias de las acciones penales, en que si la cosa solo sufría un deterioro, por ejemplo, el demandado debía pagar el más alto valor de la cosa. En un sentido similar, Volterra (1988) 561. 
Esta posición está muy vinculada con la idea, muy claramente expresada por Castresana, quien indica: "Por otra parte la estimación judicial del daño aquiliano tiene que ver con la progresiva sustitución del originario carácter penal de la actio legis Aquiliae por la función reipersecutoria de la misma'27. En verdad, estos razonamientos han sido planteados también como parte de la tesis que sobre el principio id quod interest ha desarrollado Valditara, según quien la evolución de la jurisprudencia en la valoración de los perjuicios, desde el valor del precio de mercado del bien hasta el criterio de la utilitas, mediante acciones in factum y terminando en el principio del id quod interest, producirá la modificación del carácter puramente penal de la acción aquiliana; así, la acción aquiliana no cesará su carácter penal desde el punto vista del régimen procesal, garantizando este mismo hecho el "mayor valor" con el que se gravaba al dañante, pero irá mutando su carácter como consecuencia de la evolución en la valoración de los perjuicios ${ }^{28}$.

Así estas dos visiones pueden resumirse de la siguiente manera: en la tesis tradicional en relación al capítulo tercero -y sus derivaciones-, la sanción estaba referida hacia el pasado, de modo que se aplicaba con independencia del tipo de lesión sufrido por la víctima. Es natural concluir entonces que la ley tuviese un carácter originariamente penal. La valoración de los perjuicios pasó paulatinamente desde la estimación del objeto dañado al principio id quod interest. Si, en cambio, se estima que el capítulo tercero contenía una sanción que debía computarse hacia el futuro, se sigue de ahí que el carácter de la ley era básicamente resarcitorio y que el capítulo tercero contenía en sí mismo el principio id quod interest, incorporándose dicho principio al capítulo primero, como consecuencia de la interpretación extensiva de la que fue objeto la ley ${ }^{29}$.

Castresana (2001) 37.

Valditara, Giuseppe (1992). Superamento dell'aestimatio rei nella valutazione del danno aquiliano ed estensione della tutela ai non domini. Milano: Giuffrè Editore, pp 184 y ss. FERRINI, Contardo (1930). La legitimazione attiva nell' 'actio legis Aquiliae. Opere di Contardo Ferrini. Volumen Quinto. Milano: Ulrico Hoepli, pp 192-193 ha argumentando de manera interesante con relación con el carácter penal originario de la acción. Sostiene que esta era otorgada al actual propietario y que aun cuando este dejaba de serlo, conservaba la acción, por cuanto esta estaba tenía por objeto reintegrar la ofensa hecho al dominio violado y no simplemente reparar el daño económico causado.

Daube, David (1948). "On the use of the term damnum". En AA.VV.: Studi in onore di Siro Solazzi. Napoli: Casa Editriche Eugenio Jovene, pp 139 y ss. Dado que el capítulo primero solo contenía una hipótesis concreta, estableciendo una sanción fija, el término damnum solo fue ocupado en el capítulo tercero -para referirse al primero, los autores solo habrían ocupado la expresión occidere-. Así, dicho capítulo contendría el principio del id quod interest, pues habría permitido la valoración de los menoscabos, pérdidas y gastos efectivamente sufridos por el propietario, con independencia de la afectación material del bien -animadode su propiedad. De hecho el autor afirma que: "There exists an intimate connection between damnum and the principle of interesse"; de manera que el capítulo tercero tomaría el concepto del damnum al no haber un hecho concreto y específico al cual circunscribir la conducta, 
Sin embargo, es necesario hacer dos precisiones. De un lado, no todos los autores que defienden el carácter originariamente indemnizatorio de la lex siguen las ideas de Daube e incluso en algunos casos las rechazan. Es lo que ocurre, por ejemplo, con Pugsley, a quien hemos citado en párrafos precedentes ${ }^{30}$. En segundo lugar, debemos seńalar que algunos autores estiman que la tesis de Daube se encuentra superada, desde que toda su tesis, que según Cannata construye todo un régimen aquiliano de hechos que producen deterioro ${ }^{31}$, se basa en el cómputo del período de los 30 días del capítulo tercero hacia el futuro, según el pasaje de Ulpiano del D. 9, 2, 27, 5 y un buen número de estos autores considera que el pasaje en cuestión se debe solo a un error de transcripción del manuscrito florentino del Digesto ${ }^{32}$.

Finalmente, para otro grupo de autores, la ley tenía un carácter mixto ${ }^{33}$. Cannata, refiriéndose a la acción reipersecutoria, señala: "Il carattere reipersecutorio (sostanziale) della pena da illecito aquiliano emerge invece dal concorso esclusivo di azione contrattuale (o altra azione reipersecutoria), soluzione raggiunta dalla giurisprudenza, che costrui propriamente, in proposito, una deroga al principio del concorso fra azione penale e azione reipersecutoria, deroga basada sull'idea che l'azione aquiliana rei persecutionem continet' ${ }^{\prime 3}$. Debe recordarse nuevamente, en todo caso, como indica Fuenteseca, que: "Los delicta privata romanos (furtum, iniuria, damnum iniuria datum y rapina) obedecen al concepto de poena privata porque el delictum se consideraba como un daño privado (...) Los delitos en sentido del derecho penal moderno fueron llamados crimina y se presentan sancionados desde la época de Sila mediante proceso público (iudicium publicum)".

abandonando la pena fija, para establecer un sistema de evaluación de las pérdidas que el propietario experimentó como consecuencia de las heridas inferidas a bienes de su dominio. Por el contrario, el capítulo primero no se habría referido al principio del interés, por las razones antes señaladas, de ahí el carácter fijo de la sanción; sin embargo, el autor reconoce que posteriormente dicho "principio" fue trasladado al ámbito del capítulo primero, el que no parece haber sido adoptado hasta Neracio.

30 Pugsley (1982) 1-6 considera que los juristas clásicos utilizaron la sanción hacia al pasado, al igual que en el capítulo primero, pero tal como vimos, rechaza su fundamentación en el pretendido carácter penal de la lex. También considera que tenía un carácter indemnizatorio Kelly (1964) 82 ss y en Kelly (1971) 235-239. De otra parte, como hemos visto, VAldiTARA (1994) 822 ss, criticando las tesis antagónicas de Jolowicz-Cannata y Daube, concluye que el carácter originario del texto era penal.

31 Cannata (1995-1996) 122.

32 Ya hemos visto en este sentido a Valditara (1994) 822 y con un estudio más profundo ANKUM (1983) 179 ss.

33 Afirmando el carácter mixto, por todos Zimmermann (1996) 970. Para la hipótesis del carácter mixto de la acción como categoría introducida por el derecho justinianeo, véase Rotondi, Giovanni (1916). "Dalla lex Aquilia all art. 1151 del Cod. Civ. Ricerche storicodogmatiche". Rivista del Diritto Commerciale. No 14. pp 967-969, quien recoge estas ideas de Albertario. Note sulle azzione penali. BIDR. No 26, pp 10 y ss. 
Finalmente, sostiene igualmente que se trata de una acción de carácter mixto $^{35}$.

La acción aquiliae se presentó, sin embargo, extremadamente rígida para resolver todos los problemas que se le fueron presentando ${ }^{36}$. Al respecto, señala Pugliese: "In un primo momento prevalse un'interpretazione letterale e restrittiva del testo della lex, per cui si esclusero dal suo ámbito di applicazione tutte quelle condotte che non consistessero in un facere positivo e concreto (cosi si escluse per esempio l'applicabilità dell'actio ex lege Aquilia per dani conseguenti ad un contegno meramente omissivo), e si richiese che il danno avvenisse mediante contatto diretto fra la persona del dannegiante e la cosa e consistesse nella distribuzione o nel deterioramento materiale della cosa stessa (damnum corpore corpori datum)"37.

En efecto, la acción directa en la ley Aquilia tiene lugar cuando alguno ha causado a otro el dańo material con su propio cuerpo, respondiendo al principio denominado damnum corpore datum, es decir, que la aplicación literal de los verbos occidere, urere, frangere, rumpere, contenidos en los capítulos primero y tercero de la ley, suponía que el daño fuera ocasionado (conducta comisiva), a través de un inmediato contacto físico violento entre sujeto agente y sujeto pasivo ${ }^{38}$. Sobre esta cuestión,

Fuenteseca Degeneffe, Margarita (2001). "Una visión de la trayectoria del arbitrium damni decidendi". En A.A.V.V.: La responsabilidad civil de Roma al Derecho moderno. Burgos: Ediciones Universidad de Burgos, pp 356, 357 y 358. Concluye también el carácter mixto de la acción de la Ley Aquilia, luego de un profundo análisis, en su obra Fuenteseca Degeneffe, Margarita (1997). El delito civil en Roma y en el Derecho español. Valencia: Tirant lo Blanch, pp 171 a 176. Al respecto indica: "De la exposición anterior se deduce que no existió una rígida separación entre actio reipersecutoria y actio poenalis, sino probablemente una tercera posibilidad a la que le correspondería la denominada actio mixta, en denominación justinianea".

36 Un análisis de las acciones de la ley y su excesivo formalismo, en IHering, Rudolph (1997). El espiritu del Derecho romano. Traducción de Fernando Vela. Madrid: Marcial Pons. Pugliese (1991) 605.

38 Muy gráfico sobre esta característica de la ley es el pasaje del D. 9, 2, 7, 1: "Occisum autem accipere debemus, sive gladio sive etiam fuste vel alio telo vel manibus (si forte strangulavit eum) vel calce petiit vel capite vel qualiter qualiter" (Mas debemos entender por "muerto", tanto si lo golpeó con una espada o con un palo o con otra arma o con las manos (si quizás lo estranguló) o con el pie o con la cabeza o de cualquier otro modo"). Por eso, en un pasaje de Próculo, en D. $9,2,7,3$ se niega la acción directa al que empujó para causar daño, porque se consideró que no había matado, al no haber contacto directo con la cosa: "Proinde si quis alterius impulsu damnum dederit, Proculus scribit neque eum qui impulit teneri quia non occidit, neque eum qui impulsus est, quia damnum inuiria non dedit: secundum quod in factum actio erit danda in eum qui impulit" ("De ahi que si alguien causa daño empujado por otro, escribe Próculo que no queda obligado ni el que empujó porque no mató, ni el empujado porque no causó daño con injusticia. Según esto ha de darse una acción por el hecho contra el que empujó). En verdad este pasaje y otros, como el de Labeón (D. 9, 2, 9, caso de la comadrona; D. 9, 2, 11, el caso del barbero; D. 9, 2, 11, 1), son aplicación del criterio general enunciado por Celso, quien diferencia entre matar, en cuyo caso se otorga una acción directa o se da ocasión a la muerte, para el que se concede una actio in factum. Vid supra nota 4, pp 2 y 3.

Por lo que atańe al capítulo tercero, el principio del damnum corpore corpori queda establecido en D. 9, 2, 27, 6: "Si quis igitur non occiderit hominem vel pecudem, sed usserit fregerit 
con gran acierto, comenta Arangio Ruiz que: "El daño previsto por la lex Aquilia es solamente el causado corpore corpori, es decir, el producido con el esfuerzo muscular del delincuente a la cosa considerada en su estructura fisica. La sanción de la ley no tiene lugar, en consecuencia, por falta de daño corpo$r e$, si se encierra el ganado en un establo para hacerlo morir de hambre, o si se persuade a un esclavo de que suba a un árbol, ocasionándole de esa manera la caida y muerte (Gayo, III, 219) '39. Además, según hemos analizado, desde que la ley tenía como objeto la protección del propietario, a este competía el ejercicio de la acción, en principio ${ }^{40}$. Es por estas razones que la ley Aquilia se considera un típico ejemplo del formalismo que había caracterizado la jurisprudencia posterior a las XII Tablas.

Para dar solución a los casos presentados, la jurisprudencia pretoriana comenzó a ampliar el ámbito de aplicación de la lex Aquilia, mediante las acciones útiles y las acciones in factum. En el párrafo siguiente abordaremos ambas brevemente ${ }^{41}$. El objeto de este trabajo es solo dar cuenta de las principales discusiones que existen en relación a dichos conceptos y como ellos se trasladan a la lex Aquilia. Por razones de extensión, en con-

ruperit, sine dubio ex his verbis legis agendum erit, proinde si facem servo meo obieceris et eum adusseris, teneberis mihi" ("Por consiguiente, si alguno no hubiese matado a un esclavo o res, pero hubiese quemado, quebrado o roto, habrá que demandar sin duda según estas palabras de la ley. De abi que si arrimases una tea a mi esclavo y lo quemases me quedas obligado"). Fue el verbo rumpere y su interpretación como corrumpere el que incorporando los otros dos verbos del capítulo, urere y frangere, permitirá la ampliación del ámbito normativo de la ley.

Arangio Ruiz, Vicenzo (1986). Instituciones de Derecho Romano. Traducción de la 10a Edición italiana por José Caramés Ferro. Reimpresión $1^{\text {a }}$ Edición. Buenos Aires: Depalma, p 418. En este sentido, Schipani, Sandro (1969). Responsabilità "Ex Lege Aquilia". Criteri di imputazione e problema della "culpa". Torino. Giappichelli Editore, pp 47-49 y Betri, Emilio (1962). Istituzioni di Diritto Romano. Padova: Cedam, Vol. II, part. I, pp 512-513. Trata especialmente el principio del damnum corpore datum, Zilioto (2000) 6 ss. Al respecto, la autora señala: "Nella prospettiva dell'estensione della tutela aquiliana, ciò che interessa è che Gaio dica che l'actio legis Aquiliae veniva concessa solo contro chi avesse provocado un danno corpore suo".

40 El D. 9, 2, 11, 6 seńala: "Legis autem Aquiliae action ero competit, hoc est domino" ("La acción de la ley Aquilia compete al "amo", esto es, al propietario").

41 Como lo expone gráficamente Schrage, Eltjo (2001). "Negligence. A comparative and historical introduction to a legal concept". En A.A.V.V. Negligence. The comparative legal history of the Law of Torts. Berlin: Duncker \& Humblot, p 18: "The history of the actio legis Aquiliae, analogously in Antiquity and in the Middle Ages, is characterized by a continuous extension of the interpretation of the requirements for this action". Como senala Albanese, Bernardo (1992). "Recensioni critiche a Valditara, Superamento dell'aestimatio rei nella valutazione del danno aquiliano ed estensione della tutela ai non domini". IURA. № 43, p 244, la obra jurisprudencial fue particularmente incisiva sobre todo en orden a cuatro perfiles en relación con los capítulos primero y tercero de la ley: a) superación de los límites impuestos por los verbos usados para describir la actividad dañosa: occidere, en el capítulo primero; urere, frangere, rumpere, en el tercero; b) desarrollo de una vasta perspectiva de responsabilidad, predicada en términos de iniuria hasta la refinada perspectiva de la culpa; c) paso de una aestimatio fundada sobre el precio de mercado del objeto del dańo y de una valoración coincidente, a veces, con el interés subjetivo del dañado; d) extensión del resarcimiento del daño a sujetos distintos del propietario. 
secuencia, no podremos detenernos en el estudio pormenorizado de las extensiones decretales de los verbos, especialmente desde occidere a causam mortis praestare y desde rumpere hasta corrumpere.

\section{2) LAS AMPLIACIÓN PRETORIA: ACCIONES IN FACTUM Y ÚTILES}

En primer término, debemos hacer una precisión en cuanto al concepto de estas acciones. Como es sabido por todos, los jurisconsultos romanos no se dedicaron a la construcción de categorías dogmáticas abstractas, sino, por el contrario, su genio radica en la construcción de soluciones para casos determinados, que permitieron, paso a paso, la elaboración de la ciencia jurídica posterior, especialmente en lo que al derecho privado se refiere. Esto explica que en Roma no existiese una separación entre los aspectos sustantivos y procesales del derecho, de manera que ambas cuestiones siempre se presentaron de manera indisoluble. Por ello, para hablar de la evolución de cualquier acción, es necesario conocer el procedimiento en la que esta se encuadraba ${ }^{42}$.

Así, como hemos visto, una primera etapa estuvo marcada por las acciones de la ley. En el caso de la lex Aquilia, la manus iniectio, procedimiento posteriormente modificado por la actividad pretoria, especialmente por los pretores peregrinos, quienes debían resolver los conflictos de sujetos que no eran ciudadanos romanos o entre estos y extranjeros.

El procedimiento al que se ajustaba la decisión de estos conflictos no era el de la ley, pues este se aplicaba solo a los ciudadanos, de manera que estos pretores comenzaron a desarrollar fórmulas o modelos de litigios que se sometían a su decisión. Como explica Arangio, la expresión fórmulas tuvo básicamente dos significados técnicos. Por un lado, la fórmula era un documento redactado por el magistrado, con la colaboración de las partes, en el que se concretaban las pretensiones de estas y las cuestiones sobre las que iba decidir el magistrado. En segundo término, como dice el autor, era: "un texto preparado con anterioridad por el magistrado y publicado en su edicto con la finalidad de señalar, partiendo de una hipótesis arbitrariamente elegida, todo lo que será esencial en las fórmulas concernientes a una cierta categoría de litigios, $y$, al propio tiempo, servir como modelo profundamente inalterable con ocasión de los procesos que van a presentarse ante su jurisdicción durante la anualidad de su cargo ${ }^{2 \nsucceq 3}$. Paulatinamente dichas fórmulas

Un análisis de la jurisprudencia romana y del carácter de los jurisconsultos puede encontrarse, entre otros en García Garrido, Manuel (1965). Casuismo y jurisprudencia romana. Pleitos famosos del Digesto. Vigo: Tipográfica Faro de Vigo y en Ortega Carrillo del Albornoz, Antonio; Camacho Evangelista, Fermin (1985). Juristas romanos y práctica jurisprudencial. Granada: Ediciones Tat.

Arangio-Ruiz (1945) 54. 
fueron incorporadas al ius civile, primero por la ley Ebucia -que marca el comienzo de la época del procedimiento formulario y contemplaba la opción entre acciones de la ley y el formulario-; más tarde, con las leyes julianas, se establece como único procedimiento el formulario.

De acuerdo con el esquema de D'ors, que es el que seguiremos, las fórmulas podían agruparse o clasificarse de la siguiente manera: un primer grupo correspondía a fórmulas de acciones civiles derivadas de la antiguas legis actiones. Un segundo grupo estaba constituido por acciones pretorias que se anunciaban en el Edicto (también denominadas honorarias, en atención a que también dictaban tales fórmulas los edictos curules). A su vez, las acciones honorarias eran de 3 tipos: a) acciones de ficción, por la que se mandaba al juez dar algo por existente cuando no existía; o por inexistente cuando existía. De esta manera se conseguía un resultado cuando el Derecho civil lo impedía. Estas acciones corresponderían a la denominación de acciones útiles; b) las acciones con trasposición de personas, en las que la condemnatio se refería a una persona que sustituía a la que aparecía mencionada en la intentio; c) las acciones in factum, referidas siempre a un hecho, mediante las cuales el magistrado sancionaba una conducta, aunque no estuviera reprimida en el ius civile. Son las denominadas acciones in factum conceptae ${ }^{44,45}$.

44 D'ors (1997) 126-128. Es la nomenclatura que aparece, para algunas definiciones, en algunos diccionarios de Derecho romano. Por ejemplo, en el Berger, Adolf (1953). Encyclopedic Dictionary of Roman Law. Philadelphia: The American Philosophical Sociery, p 346 se restringe la acción in factum solo a las conceptae, aun cuando respecto de las útiles hay una definición bastante parca, que no se identifica con las ficticias: "Actions introduced through the activity of preators and jurists by modification of an already existing formula to cover legal situations and transactions for which the original formula did not suffice. The mechanism of the actiones utiles contributed considerably to the development of the law". En TORrent Ruiz, Armando (2005). Diccionario de Derecho Romano. Madrid: Edisofer, pp 63-64, se definen las actiones ficticiae como aquellas que se basaban en la existencia de algún requisito civilístico, agregando que eran acciones útiles las que contenían una cláusula en la intentio solicitando al juez que juzgara sobre la base de una ficción jurídica. Por el contrario, las acciones in factum se identificaban con las decretales y no con las edictales o conceptae, como en la fórmula propuesta. Al respecto, seńala: "Constituyen una especie de acciones pretorias. Cuando el supuesto en que el actor basaba su demanda no tenía apoyo en las normas civilisticas, el pretor en los dos últimos siglos de la República concedia el ejercicio de una actio por el hecho mismo (in factum) que consideraba digno de protección juridica, de modo que la situación juridica protegida emanaba de la autoridad del magistrado por lo que la concesión de la acción (datio actionis) era discrecional. Eran acciones decretales que los juristas preferian denominar actiones in factum: acciones dadas en el caso concreto, por el hecho a enjuiciar". De manera coincidente había definido antes las acciones decretales. En cuanto a las edictales, que son las que en el esquema que seguimos se denominan propiamente in factum, o, más precisamente in factum conceptae, nos indica: "Con este nombre se conocen a todas las acciones, bien con fórmula civilistica bien con fórmula propiamente honoraria, previstas en el edicto. Las partes tienen si no un derecho absoluto si una expectativa fundada a que se les concediera la acción la acción requerida".

Es también el criterio que sigue Arangio-Ruiz (1945) 78 ss, aun cuando apreciamos cierto matiz de diferencia con D'ors. Para Arangio-Ruiz, hubo 3 clases de acciones honorarias que se tradujeron en innovaciones por retoques en las fórmulas de acciones civiles: la que denomina "transferencia de condena", que no es más que la fórmula por trasposición de personas; en un segundo grupo, los que denomina "retoques" algo más complicados, sirvieron 
Esta es la idea que recoge Emilio Valiño, para proponer un concepto más amplio de las mismas. Utiliza el concepto de acciones útiles como sinónimo de ficticias y así no solo las emplea para los casos en los que se extendía la legitimación de sujetos, sino que aquellas en las que se ampliaba también el campo de aplicación de la ley en relación a la conductas materiales de los capítulos primero y tercero, lo que otros autores denominan actio in factum, pues estas últimas quedan así reducidas solo a las concedidas por el pretor en su Edicto o por su decretum. Señala el autor que: "Empezando por estas últimas -se refiere a las ficticias-diremos que son conocidas por el Pretor en su Edicto o por decretum (normalmente contra el autor de un hecho doloso que se estima digno de sanción), sin que dichos medios judiciales tengan una acción básica en la que pueden apoyarse; es decir, que el Pretor las concede como un complemento de otras acciones edictales, pero sin que su fórmula tenga en principio nada que ver con la de aquella. El hecho de que algunas poquísimas acciones in factum aparezcan concedidas como uitiles, sin lugar a dudas se debe a una alteración del texto clásico, puesto que las ac-

para proteger a quien había contratado con un esclavo o con un hijo de familia con conocimiento del padre de familia o con ventaja económica para aquel. Son las acciones que los romanos llamaron actiones adiecticiae qualitatis. Por último, el tercer grupo estaría constituido por las acciones ficticias, que operaron cuando una relación jurídica querida por ambas partes o por una que ha obrado de buena fe, no surgía por falta de alguna de las condiciones exigidas por el derecho objetivo. En tal caso, el pretor podía considerar digna de protección la relación y ordenar al juez colocarse en la situación que existiese la condición que faltaba. Como un grupo completamente al margen, considerándolos como nuevas fórmulas introducidas por el pretor y no meros retoques del ius civile, considera las acciones in factum conceptae. Estas ideas son bastante coincidentes con la explicación que sobre su fundamento expone Guzmán Brito, Alejandro (1978). "Sobre el objeto de las ficciones pretorias". Revista de Estudios Histórico-Jurídicos. № 3, pp 51 y ss. Para este autor, la ficción, como instrumento de técnica formularia, se empleaba para producir determinados efectos jurídicos para cuya producción se alzaba en contra un elemento o cualidad jurídicos, prescritos por el derecho civil. Entonces, la manera de pasar sobre ellos era pasar su existencia o inexistencia. Por el contrario, si el defecto o exceso impedientes de la producción de determinados efectos estaba constituido por hechos del mundo material, entonces lo propio era dar una fórmula in factum, en la cual se supeditase la condena a la verificación de los hechos que interesaba reconocer como relevantes, describiendo la correspondiente fórmula. Dado que los hechos se imponen, el magistrado no podía crear una fórmula ficta.

En cuanto a las acciones in factum, Martín Minguijón, Ana Rosa (2001). Fórmulas reconstruidas y acciones in factum conceptae. Madrid: Dykinson, pp 4; 13-14, distingue entre acciones in factum edictales y decretales: "La clasificación más genérica de acciones in factum es la que distingue entre acciones in factum edictales y decretales. Las primeras eran propuestas en cláusulas que se incorporan al edicto el pretor y son, en términos precisos, actiones in factum conceptae, en contraposición con las segundas que se concedian para supuestos concretos, que, en la mayoria de las veces, suponian la extensión de una acción ya existente". La autora dedica su trabajo únicamente a las acciones in factum conceptae y, en consecuencia, no se preocupa de distinguir estas acciones de las útiles. Una explicación similar de las acciones in factum en Zilioto (2000) 79 ss. Señala que en una primera acepción, la expresión indica la estructura formularia de la acción pretoria; así la acción con formula in factum conceptae. En la segunda acepción, la expresión indica la circunstancia que la acción es concedida por el pretor para un caso concreto, cuando falla una acción edictal que tutela determinadas situaciones. 
ciones básicas que aparecen como útiles, son todas acciones ius conceptae, cuyo formalismo trata de salvar el Pretor, en determinados casos concretos, ordenando al juez que se sirva de las ficciones, pues la existencia de estas presupone necesariamente un obstáculo del ius civile que debe ser evitado, en tanto que no resulta imaginable que una acción in factum se extienda a un nuevo caso, pues lo más práctico es que para este dé el pretor otra actio in factum distinta" "46.

No obstante la claridad de estas exposiciones, como indica MartínMinguinjón, falta un concepto unánime y pacífico sobre el concepto de acciones ficticias ${ }^{47}$. La cuestión está en cuál es el alcance que se le da al concepto de acciones útiles y si estas se identifican o no con las acciones ficticias y su diferenciación con las acciones in factum ${ }^{48}$. Frente a la posición que hemos examinado, que nos parece la de mayor claridad, otro grupo de autores considera que, en términos generales, las acciones útiles se referían a una categoría de acción y no a un supuesto concreto. Se contraponía con la acción directa, en razón de su utilidad. Se trataba de una expresión que indicaba la idea de eficacia, que designaba la extensión de una acción ya existente, de forma que permitiera la tutela de situaciones que la acción directa no contemplaba originalmente, y, en este sentido, a veces se equiparaba con las denominadas fórmulas in factum y comprendía, por tanto, no solo las acciones ficticias, sino las acciones por trasposición de personas y hasta las in factum ${ }^{49}$.

Desde luego, tales discusiones, con algunos marcados matices, se trasladan al campo de la lex Aquilia, pero especialmente para distinguir o equiparar las acciones in factum de las acciones útiles. $\mathrm{Al}$ respecto, nuevamente, hemos encontrado una disparidad total entre los autores ${ }^{50}$. Mientras para algunos no existe una diferencia sustancial, tratándolas de manera indiferenciada, otros distinguen ambas acciones desde distintos

46 Valiño, Emilio (1974). Acciones útiles. Pamplona: Ediciones Universidad de Navarra, pp 23-24.

47 Martín Minguijón, Ana Rosa (2001). Acciones ficticias y acciones adyecticias. Fórmulas. Madrid: Dykinson, pp 29-30.

48 Un buen resumen de las posiciones doctrinarias en relación con las 3 categorías de acciones puede consultarse en Mercogliano, Felice (2001). Actiones ficticiae. Tipologia e datazione. Napoli: Pubblicazioni dell'Università di Camerino, pp 45 a 60.

49 Esta es precisamente la idea de MarTín (2001), 14; 25. En un sentido similar y diversamente a Valińo, sostiene Zııютот (2000) 84: "Il problema interpretativo posto dalla calificazione di una azione come utilis è delicato dato che, como è noto, nelle fonti manca ogni definizione di actio utilis (...) Perciò si debe ritenere che fossero utiles non solo le azioni fittizie, ma tutte le azioni che atraverso una diversa modifica della struttura formulare (come la trasposizione di soggetti o la costruzione dell'intentio in factum) servissero a superare un impedimento alla concessione di una azione esistente. Utilis, cioè, alluderebbe alla técnica di "adattamento" della formula, più che ad uno specifico meccanismo di adattamento".

50 Para hacernos una idea de dicha disparidad, basta analizar el texto de Zilioto (2000) 61 78, en la que trata 6 tesis en relación con la materia: la de Albanese, la de Valiño, la de Von Lütow, la de Sotty, la de Selb y la de Santoro. Nos referiremos muy brevemente a algunas de ellas en el cuerpo de este trabajo. 
puntos de vista, sea ampliando el ámbito de aplicación de las acciones útiles y reduciendo el campo de las in factum a las acciones in factum edictales conceptae, ya sea remitiéndose exclusivamente a las acciones in factum, dejando de lado las útiles, sea describiendo distintos radios de acción para ambas, desde diversos puntos de vista. En esta última perspectiva, algunos estiman que mientras las útiles ampliaron el ámbito de legitimados de la ley, las in factum extendieron las acciones materiales de la ley y el principio damnum corpore corpori. Finalmente, otros sitúan ambas acciones en este último aspecto, es decir, en la ampliación del principio damnum corpori corpore ${ }^{51}$. Veamos algunas de estas opiniones.

51 Es una obviedad decir que tales discusiones se generan porque no existe claridad en los textos, pero no está de más señalar que hay algunas normas que con carácter general señalan cuándo una acción debe ser considerada in factum y cuándo acción útil. Tal vez la norma que más discusiones ha generado, desde la cual, por ejemplo, Albanese construye toda su teoría, en la de Gai. 3, 219, según la cual: "Ceterum placuit ita demum ex ista lege actionem esse, si quis corpore suo damnum dederit, ideoque alio modo damno dato utiles actiones dantur, uelut si quis alienum hominem aut pecudem incluserit et fame necauerit, aut iumentum tam uehementer egerit, ut rumperetur; item si quis alieno seruo persuaserit, ut in arborem ascenderet uel in puteum descenderet, et is, si ascendendo aut descendendo ceciderit, aut mortuus fuerit aut aliqua parte corporis laesus sit. Sed si quis alienum seruum de ponte aut ripa in flume proiecerit et is suffocatus fuerit, hic quoque corpore suo damnum dedisse eo quod proiecerit, non difficiliter intellegi potest" " "Se ha admitido que en virtud de esta ley la acción se puede ejercitar solo si alguien causa el daño directamente con su cuerpo, y por esto, para un daño causado de otro modo, se conceden acciones útiles, como, por ejemplo, si alguien encierra y deja morir de hambre y un esclavo o una cabeza de ganado que son de otro, o si persuade a un esclavo ajeno para que suba a un árbol o baje a un pozo, y este, subiendo o bajando, se cae y se mata o se lesiona alguna parte del cuerpo. Por el contrario, se puede entender fácilmente que si alguien arroja a esclavo ajeno desde un puente o desde la orilla al rio, y este perece ahogado, aqui también se ha causado el daño con el propio cuerpo a aquel a quien se empujo").

Enseguida, hay otros dos textos interesantes. En lo que respecta a las acciones útiles, el pasaje muy breve de Ulpiano, D. 19, 5, 21 señala: "Quotiens deficit actio vel exceptio, utili actio vel exceptio est" " "Siempre que falte una acción o excepción hay acción o excepción útil). En lo que respecta a las acciones in factum, el texto de Mucio, en D. 19, 5, 11 indica: "Quia actionum non plenus numerus esset, ideo plerumque actiones in factum desiderantur, sed et eas actiones, quae legibus proditae sunt, si lex iusta ac necessaria sit, supplet praetor in eo quod legi deest: quod facit in lege Aquilia reddendo actiones in factum accommodatas legi Aquiliae, idque utilitas eius legis exigit" ("Puesto que el número de las acciones no es completo, por ello se requieren muchas veces acciones por el hecho. Pero también aquellas acciones que nos dan las leyes, si la ley es justa y necesaria, las suple el pretor en aquellos que falta a la ley. Lo que hace en la ley Aquilia, dando acciones por el hecho acomodadas a la ley Aquilia, y asi lo exige la aplicación práctica de esta ley"). Sobre esta cuestión, MacCormack (1975) 40-43, señala que existía una diferencia entre acciones in factum y actio in factum ad exemplum y que la agregación de la frase no era fortuita. Indica que la diferencia radicaba en que, cuando se otorgaba una simple actio in factum, sin incluir ninguna calificación, debía presumirse que la acción no tenía las características de la acción de la ley y, en caso que el demandado negara su responsabilidad, no podía ser condenado a una indemnización doble. Por el contrario, una actio in factum ad exemplum o una frase similar, significaba que la acción seguía el modelo de la ley Aquilia, pero era otorgada para los supuestos en los que no habia contacto físico entre el propietario dañado y la persona que era hecha responsable o bien cuando se otorgaba la acción a una persona distinta del propietario, con lo que asimila este tipo de acciones a las denominadas útiles, como veremos. Una opinión similar sostiene ArNò, Carlo (1934). "Legis 
Comencemos por la de Álvaro D'ors, que nuevamente es la que nos parece la más acertada. Para este autor el pretor amplió esta acción en tres sentidos: a) las acciones in factum fueron otorgadas para sancionar las conductas en las que no se había causado corporalmente el daño, pero la conducta había dado ocasión para que el perjuicio se produjera; b) las acciones útiles se otorgaron para ampliar el círculo de legitimarios, pues la ley confería originalmente la acción solo al propietario; c) finalmente, cuando la víctima no era un esclavo, sino una persona libre y no le interesaba la acción de lesiones, se hablaba también de una actio legis Aquiliae utilis. Agrega: "De esta actio utilis se habla en D., 9,2,13pr., y viene a ser confirmada por una glosa marginal griega de Pap. Soc. It. 1449 recto (que conserva el texto de Ulp. 19,2,13,4; el caso del maestro zapatero que deja tuerto de un golpe de horma a un aprendiz libre), en la que se aclara que la actio legis Aquiliae, en ese caso, era "útil" (cfr. D., 9,2,5,3); la contumelia seria aqui minima" 52 .

Aquiliae actio directa ero competit". BIDR. № 42, p 199: "Come Mucio ricorreva all'actio in factum accommodate legi Aquiliae per il caso di Danni ingiustamente arrecati non corpora, sia se pur tuttavia recati corpori, sia si non racati corpora, cosi a tale azione ricorreva, nei riguardi della legittimazione subbiettiva, allorquando, non potendosi sperimentare l'actio directa ex lege Aquilia, in quanto questa soltando er competit, eravi tuttavia chi, pur non essendo propietario, aveva bien interesse che la cosa non venisse danneggiata, risentendo dal daneggiamento un danno patrimoniale. E per tal modo si presenta in diritto muciano un vasto campo, in cui trova la sua applicazione questactio muciana legi Aquiliae acommodata". Contra estas ideas, BARTON, J.L (1974), "The Lex Aquilia and Decretal Actions". En Watson, Alan (ed.): Essays in Legal History for David Daube. Edinburgh: Scottisch Academic Press, pp 15 y ss, para quien la denominación in factum no puede corresponder a ningún modelo de acciones determinado. Los ejemplos de acciones in factum ad exemplum son raros, pero pueden encontrarse unos pocos. Siguiendo la tesis de MacCormack, los casos en los que no hay contacto físico entre dañante y dañado se encuentran en el texto de Neratio, en D. 9, 2, 53: "Boves alienos in angustum locum coegisti eoque effectum est, ut deicerentur: datur in te ad exemplum legis Aquiliae in factum actio" ("Metiste bueyes ajenos en un paso estrecho, y con ello se precipitaron: se da contra ti la acción por el hecho a ejemplo de la ley Aquilia") y en otro muy similar de Ulpiano: "nam et si praecipitata sint pecora, utilis actio damnum iniuriae, quasi ex lege Aquilia dabitur" ("porque también si el ganado se hubiera echado por un precipicio, se dará como por la ley Aquilia la acción útil de daño con injuria"). Nótese que en el primer caso se habla de acción in factum, mientras que en el segundo, de acción útil. Para los casos de legitimación, ambos pasajes están referidos al usufructuario. En el pasaje de Ulpiano, en D. 7, 1, 17, 3 se habla de acción útil: " $S i$ quis servum occiderit, utilem actionem exemplo Aquiliae fructuario dandam numquam dubitavi" ("Nunca dude de que se debia conceder una acción útil a imitación de la ley Aquilia, en el caso de que alguien hubiese dado muerte al esclavo en usufructo"); en tanto en otro de Paulo, que veremos luego, en D. 9, 2, 12, se habla de acción a semejanza de la ley Aquilia.

52 D'ors (1997) 438. En el mismo sentido Fernández Barreiro, A; Paricio, Javier (1997). Fundamentos de Derecho Romano Privado. $3^{a}$ Edición. Madrid: Editorial Centro de Estudios Ramón Areces, pp 442-443. En un sentido similar, García Garrido (1998) 443-444, aunque con el matiz que tratándose de las acciones in factum se limita a decir que eran aquellas otorgadas en circunstancias especiales. Para BeTtI, (1962) 513, las acciones útiles tenían por objeto ampliar los legitimados para demandar perjuicios. En el mismo sentido, BurdesE, Alberto (1993). Manuale di Diritto privato romano. 4a Edición. Torino: UTET, p 618. En el texto de la ley Aquilia, todos los casos en los que se analiza la legitimación activa se refieren al otorgamiento de la acción útil cuando no se trataba del propietario. Sin embargo, hay un 
Un visión un tanto distinta tratándose de la lex Aquilia, pero más coherente con el planteamiento general delineado más arriba, es la que ofrece Arangio-Ruiz, quien equipara las acciones útiles con las in factum, desde que las primeras se analogan a las ficticias y las propiamente in factum quedan circunscritas a las in factum conceptae: "Los clásicos encontraron alguna analogía entre los casos en que la ley Aquilia era aplicable y algunos otros que quedaban fuera de ella, pero esto solamente si el requisito que faltaba era el del daño causado corpore; en tal caso concedían ampliamente, como advierte Gayo, actiones legis Aquiliae utilis o acciones in factum, de tendencias análogas. Pero frente al requisito de la lesión corpori, que expresa la más esencial característica del daño, no admitían analogías (...) En el derecho justinianeo las cosas cambian; mientras se tiende a hacer coincidir en todo con las acciones normales las acciones útiles o in factum concedidas para el daño non corpore, la analogía de la ley Aquilia es estimulada hasta abrazar los daños non corpori" 53 .

Una explicación semejante puede encontrarse en Jörs-Kunkel, según quienes las acciones in factum se concedieron para ampliar el concepto de causalidad, en los supuestos de causación mediata o dańos causados por omisión. Agregan que en las fuentes justinianeas se concedieron acciones útiles para resarcir el perjuicio a personas libres. Finalmente, explican: "Por aplicación analógica de la lex Aquilia se amplió también el círculo de personas facultadas para el ejercicio de la acción de ella derivada. Según la ley, la acción solo correspondia al erus, propietario según la interpretación (Ulp., D. 9, 2, 11, 6) de la cosa dañada. Pero el derecho clásico protegió también al usufructuario y al usuario (Ulp., D. 9, 2, 11, 10; Paulo, ed., 11), al acreedor pignoraticio y al poseedor de buena fe (Ulp., D. 9, 2, 17) por medio de actiones utiles o in factum" 54,55 .

solo pasaje, el contenido en D. 9, 2, 30, 2, en el que se habla de una acción útil no en razón de la legitimación, sino porque el dańo no era directamente inferido: Si quis alienum vinum vel frumentum consumpserit, non videtur damnum iniuria dare ideoque utilis danda est actio" ("Si alguno hubiese consumido vino o trigo ajenos no parece que causó daño injusto y, por consiguiente, hay que dar una acción útil").

Arangio Ruiz (1945) 418. En el mismo sentido, puede consultarse a Schrage (2001) 1819, tanto por los ejemplos seńalados, como el caso del esclavo que se deja morir de hambre, como por el comentario que hace a propósito del entendimiento posterior de estas acciones por los glosadores: "...then they were of the opinión that an actio utilis would lie; was-eventually - the damage not directly inflicted to the slave, the animal or the chatel, then the actio in factum was to be considered".

Jörs, Paul; Kunkel, Wolfang (1965). Derecho Romano Privado. Traducción de la 2a Edición alemana por L. Prieto Castro. Reimpresión $1^{\text {a }}$ Edición. Barcelona: Editorial Labor, pp 365-366. En un sentido similar, Schulz (1951) 591, agregando dos cuestiones interesantes, a nuestro juicio. Primero, que la actio utilis siguió siendo una acción penal, al igual que la acción directa y, en segundo término, que la actio utilis, como la acción directa, solo se otorgó en favor del propietario, pero en el período clásico fue otorgada excepcionalmente al no propietario, pero aparentemente solo si este último sufría la injuria. 
Otro punto de vista ofrece Albanese, según quien la opinión tradicional es aquella según la cual los clásicos utilizaron las expresiones actio utilis-actio in factum de manera indiferenciada, pero para este autor ambas tenían un diverso campo de aplicación. Especialmente a partir de la exégesis del pasaje gayano 3,219, pretende reconstruir el sentido de dichos términos para los clásicos. De este modo, la acción útil concurría cuando no obstante configurarse la conducta típica prevista en la ley, tanto en el capítulo primero (occidere), como el tercero (urere, frangere, rumpere), no había un contacto directo sobre el objeto dañado, es decir, que existía un damnum corpori, pero non corpore. En cambio, la acción in factum (ad exemplum) se aplicaba en el período clásico en todos aquellos casos en los que fallaba uno de los presupuestos de aplicación de la ley, sea que fallara la lesión corporal o incluso la iniuria ${ }^{56}$.

La sustitución de las acciones útiles por las in factum habría sido obra de la jurisprudencia justinianea, en el título del Digesto, pues los compiladores habrían suprimido las diferencias entre daño non corpore y corpore datum (en este sentido coincide con las apreciaciones de Arangio-Ruiz). De modo que eliminado el presupuesto de aplicación de las útiles (damno non corpore), desapareció la necesidad de dicha nomenclatura. Por tanto, la acción útil fue reemplazada por la in factum general de la época bizantina. En cambio, la utilización de actio utilis en el D. 9, 2, para referirse a la ampliación de la legitimación de la ley, se debía a un cambio de la primitiva in factum por la primera ${ }^{57}$.

En un sentido similar se pronuncia Natali, quien piensa que la acción utilis surgió para colmar lagunas de la ley, en las que no era posible la aplicación directa de la misma, en casos análogos a los contemplados en la ley y porque miraba a la misma utilitas de la actio directa. Concretamente, esta acción surgía en el caso de dańo causado corpori (es decir, en la materialidad física), pero no corpore (es decir, mediante un acto físico de lesión), solucionando problemas de causalidad mediata, aun cuando, posteriormente en el Digesto venga cambiada con la diversa denominación de actio in factum. De esta manera, la actio utilis producía los mismos efectos que la actio directa. Por el contrario, la actio in factum se otorgaba cuando se había causado un daño non corpori, es decir, cuando no se afectaba la materialidad de la cosa o esta no resulta estrictamente destruida (non corpori neque corpore), como por ejemplo si se ha hecho escapar un siervo ${ }^{58}$.

Tomo II. Obligaciones. Familia. Sucesiones, 4a reimpresión de la $18^{a}$ Edición. Madrid: Editorial Revista de Derecho Privado, p 653, en las que se detallan las ampliaciones de la jurisprudencia, especialmente en lo relativo al principio damnum corpore datum, pero en las que no se califica la acción pretoria.

56 Albanese (1950). "Studi sulla legge Aquilia". Aupa. № 21, pp 5 y ss.

57 Albanese (1950) 97 ss.

58 Natali (1970) 70 ss. Es la misma interpretación, entre otros, de Zimmermann (1996) pp 994-995, Ferrini, Contardo (1976). Diritto Penale Romano. Roma: Erma di Bretschneider, 
Con todo, desde luego no solo se trata de distinguir o equiparar las acciones in factum y las acciones útiles, sino que, además, determinar cuándo la jurisprudencia otorgaba una acción directa y cuándo, por el contrario, una acción in factum y/o uitil. La cuestión no resulta tan sencilla, pues no es posible resolver esta cuestión respondiendo simplemente

p 697 y de Corbino (2005) 153; 157: "L'actio utilis del propietario ricorre nei casi nei quali il danno da lui sofferto non è conseguenza "diretta" del comportamento che lo ha causato, e ciò o perché esso deriva da un evento sopraggiunto o peché l'azione non era rivolta a la sua res". Sin embargo, también entiende que un caso de acción útil se configura cuando el dañado no era el propietario, sino el titular de un derecho diverso. Por otra parte, cuando se refiere a las actio in factum, con cierto matiz a nuestro juicio, indica que estas acciones procedían cuando fallaban los presupuestos de aplicación de la ley. Agrega: "Il che significa o che non è stato tenuto uno dei comportamenti previsti dalla legge (l'evento è scaturito da un comportamento diverso da quello descritto dai verba legis: il che spiega anche la irrelevanza aquiliana diretta dei comportamenti puramente "omissivi"), ovvero che il danno è derivato da fati che non sono inmediatamente collegabili all'azione (tanto sotto profilo causale, quanto sotto quello anche della relazione tra comportamento e "res": il comportamento tenuto dal soggetto né è causa inmediata del danno, ni riguardava la cosa che è stata danneggiata), ovvero ancora che il danno per il quale si concede l'azione non solo non presenta i requisiti di legge, ma non guisitifica nemmeno una estensione utile della tutela da essa prevista (il che accade quando esso manca di attualità o è risentito non dal titolare di un diritto, ma dal simplice possesore)".

Un particular juicio crítico de esta división se encuentra en Barton (1974) 15 ss. Señala el autor que la posición que venimos comentando arranca de un pasaje de las Instituciones: "In a much-cited passage in Inst. 4.2.16 Justinian's compilers inform us that an Aquilian action lies only against the defendant who has caused damnum corpore suo. For damnum inflicted alio modo it is the practice to grant actions utiles. Si non corpore damnum fuerit datum neque corpus leasum fuerit there is neither an Aquilian action nor an actio utilis, and the plaintiff will therefore be obligated to bring an action in factum". Señala que Gai. 3, 219, luego de dar varios ejemplos, pasa de la responsabilidad aquiliana a la injuria. Indica que Gayo no declara textualmente que cuando habla de damnum alio modo datum debía ser tomado como la referencia solo al damnum que es causado por una injuria física sobre la propiedad corpórea del demandante, pero los compiladores claramente lo habrían creído en este sentido. Agrega que los compiladores solo nos dieron un ejemplo de actio in factum por daños sin lesión corporal, que es el caso contenido en el D., 4, 3, 7, 7, por el que un demandado libera por compasión a un esclavo de otro, que huye, respecto del cual se otorgaba una acción in factum, lo cual demostraría que el otorgamiento de dichas acciones no estaría considerado universalmente como una extensión de la actio Aquiliae en los casos de damnum sine laesione corporis. No hay nada que permita sugerir que las acciones in factum que fueron dadas al demandante tuviesen que ver con la lex Aquilia o con alguna extensión pretoria: "There is nothing here to suggest that the actio in factum given to the plaintiff had anything to do either with the lex Aquilia or with any of its praetorian extensions". Para el autor el establecimiento de las actio in factum no derivaba solo de un modelo de acción: "...but there was no general consensus of opinion about the action upon which it should be deemed to be modeled, or indeed whether it should be taken to be modeled upon anything". Cita como buen ejemplo de ello el pasaje del D. 19, 5, 23. Luego seńala que este pasaje parece demostrar que el balance se encuentra a favor de las ideas de Lenel, seguido por Rotondi, en el sentido que se encuentre al final de las sección de bonae fidei iuducia, demuestra que la actio in factum fue un temprano ejemplo de aquellas acciones pretorias que concedieron para llenar algunos huecos en el esquema romano de contratos. En suma, razona que este y otros casos, como el de D, 9, 2, 27. 21, cuando alguien tira las monedas de las mano de otro, la actio in factum era otorgada cuando no podía ser encuadrada ni en la acción del hurto, porque no fueron a parar a algún cómplice, ni en la acción de damnum, que requería, como hemos visto, una acción directa sobre el cuerpo del bien del propietario. 
que la actio directa se otorgó al amparo del principio damnum corpore corpori. Muchos son los casos en los que frente a decisiones similares algunos juristas otorgaron acciones directas y otros, in factum e incluso Próculo incurre en dos decisiones contradictorias, otorgando en uno una acción directa y en un supuesto similar, una actio in factum. La cuestión se plantea en el ámbito de la causalidad y especialmente en los problemas de causalidad mediata. Para los efectos baste decir que algunos autores están de acuerdo en que fue la culpa la que vino a permitir en repetidas ocasiones la distinción entre acciones in factum y acciones directas y que muchas veces es este elemento el que resolvía el problema causal ${ }^{59}$.

Tampoco debemos perder de vista que dichas acciones se desarrollaron en el transcurso de varios siglos, desde los juristas de la época republicana, que pueden situarse alrededor del siglo II a.C (desde Sexto Cato hasta Alfeno Varo), hasta el siglo III d.C, en que pueden encontrarse los últimos juristas de la época clásica (desde Labeón hasta Ulpiano, en el siglo III d.C.). Por eso, cualquier análisis no puede ser estrictamente lineal, ni dejar de tener en cuenta dicho aspecto histórico ${ }^{60}$. Sobre esta cuestión, por ejemplo, Watson, ha sostenido que los remedios decretales en tiempos de Alfeno no se otorgaban automáticamente, como parece haber sido con la acción de la ley. Así, en un comienzo, la ley se interpretó más elásticamente, pero con el desarrollo de las acciones decretales devino en una interpretación más estricta, aun cuando en otro trabajo advierte que el énfasis de dicha afirmación no parece correcto. La cuestión es que no parece del todo exacto afirmar que la actitud de los juristas republicanos fue la de interpretar ampliamente la ley, pero sí es seguro que los juristas de la época clásica buscaron formas de interpretación restringida de la misma. Agrega: "For one reason or another, probably based on practical considerations, they preferred to give an actio utilis or actio in factum rather than the actio legis Aquiliae. I have no explanation of the jurists' reasons to offer here, but merely want to emphasize that this excessively narrow interpretation of the lex Aquilia"61.

59) Vid supra, nota 4, pp 2-3.

60 Para una brevísima, pero aclaradora relación de los juristas romanos de las épocas republicana y clásica, puede consultarse el trabajo de OrTega Fermin (1986) pp 33-78. Un estudio de las características de los juristas en las distintas épocas puede encontrarse en CanNATA, Carlo Augusto (1974). La Giurisprudenza romana. Torino: Giamppichelli Editore y en general en la manualística histórica del Derecho romano. Pueden citarse en un lugar destacado, a nuestro juicio, Kunkel, Wolfgang (1998). Historia del Derecho romano. Traducción de la $4^{\mathrm{a}}$ edición alemana por Juan Miquel. 4a reimpresión, 9a Edición. Barcelona: Editorial Ariel. Guarino, Antonio (1998). Storia del Diritto Romano. 12 a Edición. Napoli: Editore Jovene. Arangio Ruiz, Vicente (1943). Historia del Derecho Romano. Traducción de la 2a edición italiana por Francisco De Pelsmaeker. Madrid: Editorial Reus.

61 Watson (1965) 241 ss. Estas ideas son expresadas con carácter más general en WatsoN, Alan (1969). "Narrow, rigid and literal interpretation in the later Roman Republic". TR. No 37, p 351, quien señala que hay una opinión generalizada de que los autores republi- 
Una posición un tanto distinta, pero no menos interesante, es la que ofrece Pugsley. Para él, la evidencia muestra que no existía una afición de los juristas clásicos por interpretar estrecha o restringidamente el estatuto y que, por el contrario, muchos ejemplos muestran lo contrario. Así, iniuria fue interpretada libre y extensivamente para incluir el dolo y la culpa y qué decir de la transformación de rumpere por corrumpere, al punto de incorporar incluso los otros verbos del capítulo tercero. Sin embargo, reconoce que en un punto específico se buscó la interpretación restrictiva para evitar los excesos de la ley. Así, las dificultades en la valoración de los perjuicios, especialmente la regla de consistente en el redoblamiento de la indemnización en caso de negativa, pudieron ser combatidas por una interpretación restrictiva de la ley. Esta sería la explicación de la exigencia que los daños fueran causados corpore corpori, como aparece en Gai. 3, 219 y no exigida en la ley originariamente. Esta restricción arbitraria fue compensada por el otorgamiento de las acciones útiles.

Agrega, además, que el método propuesto por Gayo no fue seguido por todos los juristas, sino solo por Juliano. Celso, seguido por Ulpiano, logró el mecanismo de la restricción a través del verbo occiderit y la conocida distinción de este con causa mortis praestare, que a diferencia de Gayo, era una interpretación restrictiva que puede extraerse del texto de la ley. En todo caso, califica el método de Celso como arbitrario y de resultados ridículos, al punto que llega a decir que le parece difícil aceptar que juristas de la talla de Celso y Labeón antes que él introdujeran intencionalmente la distinción. Más bien considera acertadamente que fue una distinción heredada y que estaban tratando de reformular ${ }^{62}$.

De otra parte, sostiene que los juristas republicanos tuvieron otra aproximación para distinguir entre acciones civiles y pretorias. Poniendo como ejemplo el caso de la yegua que había malparido al ser expulsada de la propiedad de alguno, contemplado en D. 9, 2, 39pr, indica que en el texto Quinto Mucio otorga una acción de la ley a pesar de no haber un contacto físico entre la ofensor y el dañado, de modo que concluye que el criterio de distinción era la intencionalidad de causar daño. En suma,

canos tenían una aproximación rígida a los problemas legales, opinión que, desde luego, el autor discute, por considerarla desproporcionada y unilateral, pues muchos son los ejemplos en los que la jurisprudencia republicana se mostró bastante más abierta en sus interpretaciones que la clásica. Antes, en Watson, Alan (1993). Limits of juristic decision in the Later Roman Republic recopilado Legal Origins and Legal Change. London: Hamblendon Press ya había sostenido ideas similares. La opinión opuesta ha sido tradicionalmente adjudicada a Schulz, Fritz (1963). History of Roman legal science. Oxford: Clarendon Press, p 77. Según el autor: "Our evidence as to the republican interpretation of leges is very slender (...) Still, the interpretation of the lex Aquilia does betray a clinging to the letter: thus occidere, in the first chapter, was not taken to cover every case of causam mortis praestare, and the difficulty was overcome not by adopting a more elastic interpretation, but by means of actions "on the case" (actione in factum), proposed, of course, by the jurists and accepted by the pretor". 
frente a una conducta intencional, se otorgó una acción directa; por el contrario, una acción decretal en caso de culpa y ello por una razón muy sencilla: la ley no contemplaba originariamente la negligencia y por eso en dichos supuestos fueron desarrollados por la vía pretoria ${ }^{63}$.

Finalmente, alguna palabra debe decirse sobre el método que los juristas utilizaron para resolver las cuestiones jurídicas, especialmente las cuestiones de causalidad y, consecuentemente, el análisis de los verbos y la determinación de la aplicación de la acción directa o bien de las acciones útiles o in factum. Siguiendo a MacCormack, el principal método empleado por los juristas romanos era la analogía. En la argumentación por analogía, según el autor, junto con la decisión adoptada, se citaba un caso decidido por otro jurista, el que se utilizaba para articular la conclusión en base al argumento análogo. La cuestión era tomar un asunto en que la posición legal era evidente por sí misma o bien ya había sido reiterada y concluyente, para declarar que la situación que quería resolverse, debía ser tratada de la misma forma. Dicho argumento por analogía se habría desarrollado a través de la fórmula quemadmodum, aunque podían haberse utilizado expresiones similares.

Desde este punto de vista sostiene que el grado de analogía dependía de las similitudes de los casos. Así, a menor grado de similitud, había una analogía débil y, viceversa, si el grado de identificación de los hechos era sustancial, la analogía era fuerte. Pero a veces la diferencia entre el caso sometido a decisión y el que se utilizaba para ejemplificar era tan grande que rompía la analogía. El mejor ejemplo estaría en la distinción entre causam mortis praestare y occidere, desarrollada por Celso y que constituyó el principio con arreglo al cual un grupo de asuntos indicaban cuando se otorgaba una acción directa y cuando una actio in factum. Según el autor, en la distinción de Celso: "One might say that here argument by analogy has failed. A jurist is nor able to argue that a particular state of affairs can be approximated to some other state of affairs which indisputably counts as occidere" 64 .

Precisando quizás, sobre el problema del método, la utilización del razonamiento analógico pudiera haberse derivado, a nuestro juicio

63 Pugsley (1982) 12-15. Desde una perspectiva diferente, niega dicho principio, como hemos visto, BARTON (1974) y DaUBE (1948) 98 ss. En efecto, una cuestión interesantísima que se deriva de la tesis de Daube, desde una comprensión del carácter originario de la ley como fundamentalmente resarcitorio, es la negación del principio corpore corpori. En efecto, según el autor, tanto Gayo como Justiniano, después del primero, declararon que la lex era disponible si quis corpore suo damnum dederit, que es bien distinto a sostener que en la ley se exigiera un damnum dare corpori. De esta manera: “... damnum corpori datum and, of course, damnum corpore corpori datum cannot be reconciled with the Roman usage". La expresion habría sido resultado de una introducción de los juristas medievales, desde que el daño no era utilizado para la destrucción o deterioro de las cosas, sino que para las pérdidas sufridas para el propietario. 
porque, como explica el profesor García Garrido, los juristas romanos trabajaron sobre la hipótesis de un caso original, real o inventado, resuelto por los juristas más antiguos, tratando variantes hasta llegar a la sucesiva generalización o formulación de una regla general. Esta regla es la que serviría de guía para la decisión de casos, reales o hipotéticos que constituían variantes del anterior, en algún sentido. Luego, las conexiones de una decisión anterior con el nuevo caso conectado era trabajo de la analogía. Por eso, García Garrido considera que el estudio comparado de estos casos puede permitir la reconstrucción de lo que denomina "estratos casuísticos", desde la redacción original del texto hasta las variantes abordadas por los últimos juristas ${ }^{65}$.

\section{CONCLUSIONES}

Hemos intentado hacer un sucinto repaso de las principales características de la acción que emanaba de la lex Aquilia, deteniéndonos en el carácter penal y mostrando cómo las distintas lecturas del capítulo tercero influyen en este aspecto. Por ello, aparecen claramente relacionadas las visiones del carácter penal con aquella que concibe la sanción del capítulo tercero hacia el pasado para la valoración del objeto dañado. Por el contrario, la posición que piensa en la sanción del capítulo tercero hacia el futuro, estima que dicho capítulo contenía desde su origen el principio id quod interest y que la ley no podía ser considerada como originariamente penal. Sin embargo, también hemos analizado cómo es-

La materia ha sido desarrollada en dos trabajos: García Garrido, Manuel Jesús (1988).

"Realidad y abstracción en los casos jurisprudenciales romanos (Estratos casuísticos en los supuestos de comodato de caballerías)". En A.A.V.V. Estudios en Homenaje al profesor Juan Iglesias. Madrid: Seminario de Derecho Romano. Tomo I, pp 249 ss, en el que propone la reconstrucción y posterior elevación a regla general del caso del caballo dado en comodato, desde los juristas republicanos hasta los últimos clásicos. Por ejemplo, en p 258, de manera similar a los argumentos de MarCormack, que hemos estudiado, propone que el supuesto del comodato del caballo pudo haber servido a los juristas para decidir otros semejantes o bien como ejemplo o caso guía. El otro trabajo es de un tenor un tanto distinto. En efecto, en García Garrido, Manuel Jesús (1987). "Redacciones coincidentes (leges geminatae) y casos jurisprudenciales semejantes (capita similia)". En A.A.V.V. Estudios de Derecho Romano en Honor de Alvaro D'ORS. Pamplona: Ediciones Universidad de Navarra, Tomo I, pp 517 ss. En este, como indica el título, analiza las concepciones de la doctrina sobre los casos gemelos y semejantes; efectúa una crítica a la proposición de los romanistas y propone el método de comparación de casos, analizando supuestos de compraventa de esclavos, especialmente el de la propiedad de la esclava hurtada y legada. En cualquier caso, las conclusiones son semejantes a las señaladas en el primer trabajo, es decir, que los juristas romanos se sirvieron de un caso base u originario, real o hipotético, resuelto por los primeros juristas, para sobre la base del mismo introducirle variantes, que permitiría recibir la tradición de los juristas anteriores. Un análisis de dicho método puede encontrarse en Lazo, Patricio (2004). "El método de comparación de casos: examen de sus resultados". Revista de Estudios HistóricoJurídicos. No 26. 
tas dos grandes visiones están cargadas de matices, sea porque la primera gran posición tiene variantes en cuanto a los bienes comprendidos en dicha sanción, sea porque hay opiniones escépticas o que intentan construir una tercera vía. En ambos casos, hay opiniones que transitan desde un lugar a otro tratándose de la naturaleza penal. Tomamos nota de dos ejemplos. Pugsley propone que la sanción era hacia el pasado, pero niega cualquier carácter penal a la ley. O Valditara, quien se separa de las posiciones tradicionales defendidas por Jolowicz y recientemente por Cannata y la de Daube, considera sin lugar a dudas que la ley tuvo un carácter originariamente penal.

Mayores son las discusiones cuando quiere precisarse el concepto de las acciones a través de las cuales se amplió el ámbito de aplicación de la lex Aquilia. Si ya es difícil determinar dichos conceptos en general, en la lex Aquilia varias tesis, a veces con sutiles diferencias, intentan ubicar en lugares determinados las acciones in factum y las útiles. El presente trabajo ha servido para mostrar dicha discusión y las diversas perspectivas desde la cuales puede ser analizado.

\section{BIBLIOGRAFÍA}

Albanese, Bernardo (1950). "Studi sulla legge Aquilia". Aupa. No 21.

(1970). Illecito (storia). Enciclopedia del diritto. Tomo XX. Milano: Giuffrè Editore.

(1992). "Recensioni critiche a Valditara, Superamento dell'aestimatio rei nella valutazione del danno aquiliano ed estensione della tutela ai non domini". IURA. No 43.

Albertario. Note sulle azzione penali. BIDR. No 26.

Ankum, Hans (1983). "Quanta ea res erit in diebus XXX proximis dans le troisième chapitre de la lex Aquilia: un fantasme florentin”. En A.A.V.V.: Mélanges en Hommage a Jacques Ellul. Religión, société et politique. París: Press Universitaires de France.

Arangio Ruiz, Vicente (1943). Historia del Derecho Romano. Traducción de la $2^{\text {a }}$ edición italiana por Francisco de Pelsmaeker. Madrid: Editorial Reus.

(1945). Las acciones en el derecho privado romano. Traducción de Faustino Gutiérrez Alviz. Madrid: Editorial Revista de Derecho Privado.

(1986). Instituciones de Derecho Romano. Traducción de la $10^{a}$ Edición italiana por José Caramés Ferro. Reimpresión 1a Edición. Buenos Aires. Desalma.

Arias Ramos, J.; Arias Bonet, J.A. (1994). Derecho Romano. Tomo II. Obligaciones. Familia. Sucesiones. $4^{\mathrm{a}}$ reimpresión de la $18^{\mathrm{a}}$ Edición. Madrid: Editorial Revista de Derecho Privado. 
Arnò, Carlo (1934). "Legis Aquiliae actio directa ero competit". BIDR. No 42.

Barton, J.L (1974). "The Lex Aquilia and Decretal Actions". En Watson, Alan (ed.): Essays in Legal History for David Daube. Edinburgh: Scottisch Academic Press.

Berger, Adolf (1953). Encyclopedic Dictionary of Roman Law. Philadelphia: The American Philosophical Society.

Betti, Emilio (1962). Istituzioni di Diritto Romano. Padova: Cedam, Vol. II. Bignardi, Alessandra (1997). "Frangere e rumpere nel lessico normativo en ella interpretatio prudentium". En AA.VV. Nozione, formazione $e$ interpretazione del diritto. Dall'età romana alle sperienze moderne. Ricerche dedicate al professor Filippo Gallo. Napoli: Jovene Editore: Tomo I.

Biondi, Biondo (1965). Istituzioni di Diritto Romano. 4a Edición. Milano: Giuffrè Editore.

Biscardi, Arnaldo (1967). "Sulla data della "lex Aquilia". En AA.VV.: Scritti in Memoria di Antonino Giuffrè. Milano: Giuffrè. Tomo I.

Burdese, Alberto (1993). Manuale di Diritto privato romano. 4a Edición. Torino: UTET.

Cannata, Carlo Augusto (1974). La Giurisprudenza romana. Torino: Giamppichelli Editore.

(1992). "Sul testo originale della lex Aquilia: premesse e ricostruzione del primo capo". SDHI. No 58.

(1992). "Delito y obbligazione". En AA.VV. Illecito e pena privata in età repubblicana. Napoli: Edizioni Scientifiche Italiane.

(1994). "Considerazioni sul testo e la portata originaria del secondo capo della "lex Aquilia". Index. No 22. 98-99.

(1995-1996). "Il terzo capo della "Lex Aquilia". BIDR. Nos

(1996). Sul problema della responsabilità nel Diritto Privato Romano. Catania: Librería Editriche Torre Catania.

Cardiasca, G (1974). "La portée primitive de la Loi Aquilia". En Watson, Alan (ed.). Daube Noster. Essays in legal history for David Daube. Edinburgh: Scottish Academic Press.

Castresana, Amelia (2001). Nuevas lecturas de la responsabilidad aquiliana. Salamanca: Ediciones Universidad de Salamanca.

Corbino, Alessandro (2005). Il danno qualificato e la lex Aquilia. Milano: Cedam.

Daube, David (1936). "On the third chapter of the lex Aquilia". LQR. No 52.

(1948). "On the use of the term damnum". En AA.VV.: Studi in onore di Siro Solazzi. Napoli: Casa Editriche Eugenio Jovene.

(1969). Roman Private law. Linguistic, social and philosophical aspects. Edinburgh: Edinburgh University Press. 
Díaz Bautista, Antonio (2001). "La función reipersecutoria de la poena ex Lege Aquilia”. En AA.VV. La responsabilidad civil de Roma al Derecho moderno. Burgos: Ediciones Universidad de Burgos.

D’ors, Alvaro; Hernández Tejeiro, F; Fuenteseca, P; García Garrido, M.; Burillo, J (1968). El Digesto de Justiniano. Pamplona: Aranzadi.

D’ors, Alvaro (1997). Derecho Privado Romano. 9a Edición. Pamplona: Ediciones Universidad de Navarra.

Fernández Barreiro, A. Paricio, Javier (1997). Fundamentos de Derecho Romano Privado. 3a Edición. Madrid: Editorial Centro de Estudios Ramón Areces.

Ferrini, Contardo (1930). La legitimazione attiva nell' "actio legis Aquiliae. Opere di Contardo Ferrini. Volumen Quinto. Milano: Ulrico Hoepli.

(1976). Diritto Penale Romano. Roma: Erma di Bretschneider.

Fuenteseca Degeneffe, Margarita (1997). El delito civil en Roma y en el Derecho español. Valencia: Tirant Lo Blanch.

(2001). "Una visión de la trayectoria del arbitrium damni decidendi". En A.A.V.V.: La responsabilidad civil de Roma al Derecho moderno. Burgos: Ediciones Universidad de Burgos.

García Garrido, Manuel (1965). Casuismo y jurisprudencia romana. Pleitos famosos del Digesto. Vigo: Tipográfica Faro de Vigo.

(1987). "Redacciones coincidentes (leges geminatae) y casos jurisprudenciales semejantes (capita similia)". En AA.VV. Estudios de Derecho Romano en Honor de Alvaro D'ors. Pamplona: Ediciones Universidad de Navarra: Tomo I.

(1988). "Realidad y abstracción en los casos jurisprudenciales romanos (Estratos casuísticos en los supuestos de comodato de caballerías)". En AA.VV. Estudios en Homenaje al profesor Juan Iglesias. Madrid: Seminario de Derecho Romano. Tomo I.

(1998). Derecho Privado Romano. Casos, acciones, instituciones. 7a Edición. Madrid: Editorial Dykinson.

Grosso, Giuseppe (1964). "La distinzione fra "res corporales" e "res incorporales" e il secondo capo della lex Aquilia”. En AA.VV.: Synteleia Vicenzio Arangio Ruiz. Napoli: Editore Jovene Napoli.

Guarino, Antonio (1968). "La data dalla lex Aquilia". LABEO. No 14.

(1998). Storia del Diritto Romano. 12a Edición. Napoli: Editore Jovene.

Guzmán Brito, Alejandro (1978). "Sobre el objeto de las ficciones pretorias". Revista de Estudios Histórico-Juridicos. No 3.

Hernández Tejero, Francisco (Coord); Abellan Velasco, Manuel; Arias Bonet, Juan Antonio; Iglesias Redondo, Juan; Roset EsTEVE, Jaime (1965). Instituciones de Gayo. Edición bilingüe. Madrid: Civitas. 
Ihering, Rudolph (1997). El espiritu del Derecho romano. Traducción de Fernando Vela. Madrid: Marcial Pons.

Iliffe (1958). "Thirty days hath lex Aquilia”. RIDA. $3^{\text {a }}$ serie, Tomo V.

Jolowicz, H.F, (1922). "The original scope of the lex Aquilia and the question of damages". LQR. No 38 .

Jörs, Paul. Kunkel, Wolfang (1965). Derecho Romano Privado. Traducción de la 2a Edición alemana por L. Prieto Castro. Reimpresión $1^{a}$ Edición. Barcelona: Editorial Labor.

Kelly, John (1964). "The meaning of the lex Aquilia". LQR. No 80.

(1971). "Further reflections on the lex Aquilia". En AA.VV. Studi in onore di Edoardo Volterra. Milano: Giuffrè Editore. Vol. I.

Kunkel, Wolfgang (1998). Historia del Derecho romano. Traducción de la $4^{\mathrm{a}}$ edición alemana por Juan Miquel. 4a reimpresión 9 ${ }^{\mathrm{a}}$ Edición. Barcelona: Editorial Ariel.

Lazo, Patricio (2004). "El método de comparación de casos: examen de sus resultados". Revista de Estudios Histórico-Jurídicos. No 26.

MacCormack, Geoffrey (1970). "On the third chapter of the lex Aquilia". The Irish Jurist. No 5.

(1975). "Aquilian Studies". SDHI. No 41.

(1982). "Juristic interpretation of the lex Aquilia". En AA.VV.: Studi in onore di Cesare Sanfilipo. Milano: Giuffrè Editore, Tomo I.

Martín Minguijón, Ana Rosa (2001). Fórmulas reconstruidas y acciones in factum conceptae. Madrid: Dykinson.

(2001). Acciones ficticias y acciones ayecticias. Fórmulas. Madrid: Dykinson.

Martínez SARrión, Ángel (1993). Las raices romanas de la responsabilidad por culpa. Barcelona: Editorial Bosch.

Mercogliano, Felice (2001). Actiones ficticiae. Tipologia e datazione. Napoli: Pubblicazioni dell'Università di Camerino.

Mommsen, Theodorus. Krueger, Paulus (1988). Corpus Iuris Civiles. Volumen Primum. Instituciones. Digesta. Hildesheim: Weidmann.

Natali, Nuncio (1970). La lege Aquilia ossia il damnum iniuria datum. Roma: L'erma di Bretschneider.

Ortega Carrillo del Albornoz, Antonio; Camacho Evangelista, Fermin (1985). Juristas romanos y práctica jurisprudencial. Granada: Ediciones Tat.

Pugliese, Giovanni (1991). Istituzioni di Diritto Romano. 3a Edición. Torino: Giampichelli Editore.

Pugsley, David (1982). "On the lex Aquilia and culpa". TR. No 50.

Rotondi, Giovanni (1916). "Dalla lex Aquilia all art. 1151 del Cod. Civ. Ricerche storico-dogmatiche". Rivista del Diritto Commerciale. No 14.

Schrage, Eltjo (2001). "Negligence. A comparative and historical introduction to a legal concept". En AA.VV. Negligence. The comparative legal history of the Law of Torts. Berlín: Duncker \& Humbolt. 
Schulz, Fritz (1951). Classical Roman Law. London: Clarendon Press. (1963). History of Roman legal science. Oxford: Clarendon Press.

Scialoja, Vittorio (1954). Procedimiento civil romano. Ejercicio y defensa de los derechos. Traducción Santiago Santis Melendo y Marino Ayerra Redin. Buenos Aires: Ediciones Jurídicas Europa-América.

Shipani, Sandro (1969). Responsabilità "Ex lege Aquilia". Criteri di imputazione e problema della "culpa". Torino. Giappichelli Editore.

Sном, Rodolpho (1927). Instituciones de Derecho Privado Romano. Historia y Sistema. Traducción de la $17^{\text {a }}$ Edición del alemán por W. RoCes. Madrid. Revista de Derecho Privado.

Torrent Ruiz, Armando (2005). Diccionario de Derecho Romano. Madrid: Edisofer.

Valditara, Giuseppe (1992). Superamento dell'aestimatio rei nella valutazione del danno aquiliano ed estensione della tutela ai non domini. Milano: Giuffrè Editore.

(1994). "Damnum iniuria datum". En A.A.V.V.: Derecho Romano de obligaciones. Homenaje al profesor José Luis Murga Gener. Madrid: Centro de Estudios Ramón Areces.

Valıño, Emilio (1974). Acciones útiles. Pamplona: Ediciones Universidad de Navarra.

Van Warmelo, Paul (1980). "A propos de la loi Aquilia". RIDA. No 27.

Volterra, Eduardo (1988). Instituciones de Derecho Privado Romano. Reimpresión $1^{\text {a }}$ Edición. Madrid: Civitas.

Watson, Alan (1965). The law of obligations in the later Roman republic. London: Clarendon Press.

(1969). "Narrow, rigid and literal interpretation in the later Roman Republic". TR. № 37.

(1993). Limits of juristic decision in the Later Roman Republic recopilado Legal Origins and Legal Change. London: Hamblendon Press.

(s.d.). Roman Private Law around 200 BC. Edinbugh: Edinburgh University Press.

Zilıoto, Paola (2000). L'imputazione del danno aquiliano. Tra iniuria e damnum corpore datum. Padova: Cedam.

Zimmermann, R (1996). The Law of Obligations. Roman Fundations of the Civilian Tradition. Oxford. 